\title{
Using Functional Neuroimaging to Refine the Diagnostic Construct of Borderline Personality Disorder
}

\author{
Merav H. Silverman*, S. Charles Schulz and Kathryn R. Cullen
}

University of Minnesota, Minneapolis, MN 55454, USA

\section{Correspondence to:}

Merav H. Silverman

University of Minnesota, Minneapolis

MN, 55455, USA

Tel: 612-625-2818

E-mail: silve369@umn.edu

Received: October 29, 2015

Accepted: May 17, 2016

Published: May 18, 2016

Citation: Silverman MH, Schulz SC, Cullen KR. 2016. Using Functional Neuroimaging to Refine the Diagnostic Construct of Borderline Personality Disorder.JNeuroimaging Psychiatry Neurol 1(1): 27-45.

Copyright: (C) 2016 Silverman et al. This is an Open Access article distributed under the terms of the Creative Commons Attribution 4.0 International License (CC-BY) (http:// creativecommons.org/licenses/by/4.0/) which permits commercial use, including reproduction, adaptation, and distribution of the article provided the original author and source are credited.

Published by United Scientific Group

\begin{abstract}
Borderline Personality Disorder (BPD) is a severely impairing mental disorder, characterized by affective instability, stormy interpersonal relationships, and behavioral impulsivity. Accumulating research in the past two decades has provided evidence for a neurobiological basis of mental disorders, including BPD. It has long been argued, though, that the level of clinical heterogeneity within the BPD diagnosis may be suggestive of multiple underlying neural processes and circuits. As such, the relative involvement of different sets of neural abnormalities across individuals could be informative about the possible pathophysiological mechanisms underlying different dimensions of the disorder. Task-based neuroimaging techniques, such as functional magnetic resonance imaging (fMRI), are potentially capable of teasing apart neurobiological domains of BPD by identifying the differential neural involvement of key circuits during psychological processes in relation to specific aspects of BPD symptomatology. In this paper, we review the literature on task-based fMRI in BPD with a focus on how neuroimaging studies, have revealed different neural correlates for the prominent symptom clusters (unstable interpersonal relationships, behavioral impulsivity, and emotion dysregulation) within BPD. Evidence suggests the prominence of altered neural activity in key brain networks and regions including the salience network, the default mode/theory of mind network, the central executive network, and the orbitofrontal cortex. We suggest future directions for neuroimaging and BPD research to further shed light on the pathophysiology of the disorder and the nature of the BPD diagnosis.
\end{abstract}

\section{Keywords}

Borderline personality disorder, Positron emission tomography, Functional magnetic resonance imaging (fMRI), Domains in personality disorder

\section{Introduction}

Borderline Personality Disorder (BPD) is a severe psychiatric disorder, characterized by a heterogeneous set of symptoms that result in impairment across many functional domains, including educational attainment, employment, and interpersonal relationships [1]. In addition, in part due to prominent symptoms such as suicidality and self-harm, the mortality rate for individuals with BPD is high, with an estimated suicide rate of between 5\% and 10\% [24]. Using confirmatory factor analysis of BPD symptomatology, researchers have identified three core components from which BPD symptoms are understood to relate: 1) disturbances in interpersonal relationships, 2) behavioral dysregulation and impulsivity, and 3) emotion dysregulation [5]. In addition, studies have identified unique stress-related disturbances in cognition (e.g., dissociation, mood dependent paranoia, depersonalization) in some individuals with BPD [6, 
7]. A biological basis underlying BPD has long been theorized $[8,9]$. In the past two decades, with the improvement of neuroimaging methods, it has been possible to produce strong evidence for a neurobiological basis for the disorder.

\section{BPD: A Categorical or Dimensional Construct?}

In the context of recent revisions of the Diagnostic Statistical Manual (DSM), there remains debate about how best to conceptualize and ultimately diagnose BPD. In DSMIII, DSM-IV, and DSM-IV-TR, a diagnosis of BPD was based on an individual meeting 5 of 9 symptom criteria across the aforementioned symptom domains [10-12]. In the process of the research, preparation, and writing of DSM-5, there was a heated debate about whether this polythetic, categorical approach was the optimal way to conceptualize BPD $[13,14]$. Though DSM-5 was published in 2013, this debate is ongoing and continues to the present. Critics of the categorical approach to diagnosing personality disorders (PDs) highlight some of the prevalent problems with this method. These have been enumerated elsewhere but include: rampant comorbidity among PDs (and with common mental disorders), arbitrary symptom number cut-offs to distinguish between pathology and non-pathology, and the ubiquity of non-specific 'not otherwise specified [NOS]' diagnoses which are present across all psychiatric disorders [15].

For BPD, these critiques have been particularly widespread [16]. Opponents of the categorical diagnostic system highlight the heterogeneity in the population of patients that meet criteria for BPD. Notably, based on the historic, polythetic, 5-out-of-9 criteria for BPD, there are 256 possible symptom combinations, all of which result in a diagnosis of BPD. Still, many of these symptom patterns share so little in common (e.g., two people could overlap in only one symptom yet have the same diagnosis) as to be questionable whether the diagnosis in fact describes the same clinical phenomenon. While the flaws of this diagnostic framework pose problems for the theoretical construct of BPD and for research on the disorder, they also potentially obstruct best practices for treatment; given such heterogeneity, it is debatable whether the same treatment is optimal, across the varied clinical presentations of the disorder [17].

In response to these challenges to the BPD construct, some have argued that BPD may be an illness of multiple subtypes, as is being discussed in other major illnesses such as schizophrenia $[18,19]$. Certain pharmacological studies suggest that this viewpoint may have credibility, as some classes of psychotropic medications work best in specific subtypes or symptom domains of the illness [20]. For example, one study found that in patients with BPD, aggression, but not other symptoms, improved with anticonvulsant medications [21]. Among those with BPD, a similar study found that higher trait impulsivity and state anger scores at baseline predicted a more favorable response to Divalproex (an anticonvulsant/ mood stabilizer) as a treatment for impulsive aggression [22].

Despite the debate leading up to the publication of DSM-
5 , the categorical approach to diagnosing PDs was maintained, relatively unaltered, in the main text of the manual. Still, an alternative model for diagnosing and understanding PDs was developed and proposed. This alternative proposal can be found in Section III of DSM-5 (for emerging measures and models), offering a dimensionally-based approach for assessing personality pathology $[12,23]$. In this alternative model, a diagnosis of BPD is dependent on determining a level of personality impairment (Criterion A, the assessment of which is the same across all of the PD) and a combination of personality traits empirically shown to be associated with BPD (emotional lability, anxiousness, separation insecurity, depressivity, impulsivity, risk taking, and hostility). Taken together, these traits comprise aspects of the major personality domains -- high neuroticism, disinhibition, and antagonism -- which have been found in individuals with BPD [24, 25]. These personality traits also dovetail with the symptom domains from the categorical diagnosis of $\mathrm{BPD}$, which can be found in Section II of DSM-5 and previous editions of the DSM [26]. Both the suggestion that there are sub-types within $\mathrm{BPD}$ and the move toward a dimensional, trait-based approach to assessing BPD call into question the notion that $\mathrm{BPD}$ is a unitary construct; these ideas suggest that there may be diverse components or aspects to the BPD diagnosis [27].

\section{The Clarifying Role of Task-Based Functional Neuroimaging}

Neuroimaging provides a powerful tool for examining the neural underpinnings of psychopathology, capable of shedding light on this contemporary debate in the field. Using a range of neuroimaging techniques, a growing number of studies have explored neural structural and functional differences between individuals with BPD and psychiatric or healthy control (HC) groups. In addition, studies have explored whether there might be different patterns of neural activation during tasks which tap into psychological constructs associated with specific symptoms, symptom domains, or maladaptive personality traits that comprise the BPD diagnosis. This level of inquiry uses novel techniques from neuroscience to weigh in on this long-standing tension regarding the structure of borderline personality pathology.

Varied neuroimaging methods measuring both brain structure and function, including positron emission tomography (PET), structural magnetic resonance imaging (MRI), and electroencephalography (EEG) have all been used to elucidate aspects of the neural underpinnings of BPD [28-30]. The diversity in neuroimaging techniques means that a review of the full extent of the neuroimaging and BPD literature is beyond the scope of this project. Given its utility in locating neural activity in response to specific psychological processes, this report will focus on the role that task-based functional magnetic resonance imaging (fMRI) research can play in helping to refine the conceptualization of BPD. fMRI is one of the most common neuroimaging techniques and uses blood oxygenated dependent level (BOLD) imaging to measure neural function. BOLD signal serves as an endogenous contrast, measuring the difference in magnetization between 
oxy- and deoxyhaemoglobin as a proxy for brain activity [31].

The $\mathrm{fMRI}$ literature on BPD is often summarized by the idea that BPD is a brain-based disorder resulting from failures in bottom-up and top-down brain processes [32, 33]. This theory refers to hyper-activation in regions associated with emotion generation (driven by the limbic system in regions such as the amygdala and hippocampus) and altered prefrontal activation in regions associated with emotion regulation and cognitive control (prefrontal cortex) [34, 35]. While this is an important piece of the puzzle, we argue that such a model is reductive, and obscures the nuances and diversity within the neurobiological substrates of BPD.

Research examining large-scale neurocognitive brain networks, characterized by collections of brain regions (nodes) and the connections between them (edges), can usefully elucidate cognitive and emotional dysfunctions in psychopathology [36]. Network connectivity models, instead of studying the specialized processing occurring in specific brain regions, underscore the importance of examining the contemporaneous flow of information across distributed brain systems [37]. Focusing on the varied neural processes and networks underlying the diverse symptom domains (disturbed interpersonal relationships, behavioral impulsivity, emotion dysregulation) of BPD can offer clarity about the neurobiology of the disorder and the nature of the BPD construct more generally.

\section{BPD Symptom Domains}

\section{Disturbed interpersonal relationships}

Disturbances in interpersonal relationships in BPD have been documented broadly and are suggested to be core to the pathology [38-40]. Many clinicians find that the interpersonal style characteristic of BPD is qualitatively different, and particularly challenging to treat, relative to other psychiatric disorders [41]. Disturbances in interpersonal relationships in BPD have been recognized since the inception of the diagnosis [42, 43]. Beyond challenging therapeutic relationships, individuals with $\mathrm{BPD}$ have much higher rates of social dysfunction across a range of interpersonal domains [44]. As a result, the interpersonal difficulties experienced by this population can obstruct effective treatment and impede the possibility for positive social relationships.

This aspect of BPD can be found in the diagnostic criteria; among the symptoms for BPD in DSM-5 Section II is: 'A pattern of unstable and intense interpersonal relationships characterized by alternating between extremes of idealization and devaluation.' Relationship difficulties are also captured in the alternative dimensional model of BPD in DSM-5, which includes impairment in personality functioning, evidenced by failures in empathy and intimacy, as diagnostic features of Criterion A for assessing PDs [12]. Research suggests that the diagnostic criteria of unstable interpersonal relationships may be familial and moderately heritable $[45,46]$.

Someresearchersviewdisturbed interpersonal relationships as central to borderline pathology, more so than other symptom domains, arguing that affective instability and behavioral impulsivity may be non-specific features of psychopathology [47]. Furthermore, disturbed interpersonal relationships may be the best discriminator of a BPD diagnosis, relative to the other symptom domains $[38,39]$. Beyond the importance of this criteria to assessment, diagnosis, and treatment of BPD, problematic interpersonal relationships serve to exacerbate certain of the other dimensions of the disorder (e.g., high interpersonal reactivity during childhood and adolescence might influence parenting that in turn aggravates borderline symptoms related to emotion dysregulation or behavioral impulsivity).

It has been suggested that the observable disturbances in interpersonal relationships in BPD may in fact be attributable to underlying deficits in aspects of social cognition in this population. Human social cognition refers to the ability to accurately perceive and process conscious and unconscious social signals [48]. Functional impairment in interpersonal relationships in individuals with BPD may be related to fundamental deficits in processing social information [49]. Much of the research on social cognition in BPD has focused on two aspects: impaired theory of mind (ToM) and altered emotion sensitivity and recognition. ToM, which has been alternatively called cognitive empathy or mentalizing [50], refers to the ability to recognize and differentiate the mental states (intentions, wishes, desires) that belong to oneself and those that belong to others. Within the clinical literature on BPD, the term mentalizing has gained traction, largely because of its relevance to BPD treatment (discussed below), but the terms (ToM, mentalizing, cognitive empathy) are often used interchangeably. Using functional neuroimaging, a growing number of studies have explored the neural activation associated with these aspects of social cognition (ToM, emotion sensitivity and recognition) and have found evidence for altered neural patterns in individuals with BPD, providing a possible explanation for the observable functional impairments.

\section{ToM and Mentalization in BPD}

Fonagy and Bateman [51], prominent theorists on the developmental etiology and processes of BPD, argue that failure to develop the capacity to mentalize is central to the onset of BPD symptomatology. In the context of insecure early attachment relationships, stress, trauma, or malevolence impede a child's ability to mentalize. In particular, failure on the part of the caretaker during early years to mirror the mental and emotional states of the child inhibits the child's ability to recognize and make sense of their own mental states and the mental states of others. Bateman and Fonagy argue that this early failure to reach the social cognition milestone serves as the underlying factor for BPD symptomatology. Linehan (1993) [52] posits a similar idea, namely that invalidation of early emotions and experiences creates a situation in which the child (and then adult) turns to others in order to define the child's internal reality. This impairs the child's ability to identify the child's own inner states and to differentiate the child's inner states from the inner states of other people. Though these theories offer different etiologies, they seek to explain the phenomenon of failures of ToM in BPD.

Bateman and Fonagy [53] have developed one of a small 
number of effective evidence based treatments (EBTs) for $\mathrm{BPD}$, mentalization based therapy (MBT), which directly intervenes to treat the mentalization deficits in individuals with BPD. In the treatment, the therapist works to help the patient develop a stable sense of self while also helping the patient learn the difference between the patient's own thoughts and feelings and the thoughts and feelings of others (in particular the therapist's). Evidence suggests that this form of therapy may be more effective at reducing suicidality, self-harm, selfreported symptoms, and self-reported social and adjustment problems, relative to a structured protocol for treating BPD [54].

Researchers exploring the exact nature of the mentalizing deficits in BPD have debated the details. Some researchers find evidence for a phenomenon referred to as "hypermentalizing," in which mentalizing errors are believed to result from the over-interpretation and attribution of mental states or intentions of others $[55,56]$. Others suggest that patients suffer from an inability to mentalize [57]. The behavioral evidence supporting altered mentalizing and ToM in BPD has been mixed, as well. Some studies have found that individuals with BPD in fact have an increased ability to recognize the affective states of others, whereas other studies have found a reduced capacity or no difference between individuals with $\mathrm{BPD}$ relative to $\mathrm{HCs}[58,59]$.

\section{Neural Networks, ToM, and BPD}

While clinical evidence, as well as mixed results from behavioral research, have suggested that altered ToM may play a role in the development and maintenance of BPD, a small but growing area of neuroimaging research has used $\mathrm{fMRI}$ to identify altered neural activation associated with ToM in BPD. In the current project, we include in this section studies, which: 1) used tasks explicitly exploring ToM/mentalizing/cognitive empathy, 2) used tasks assessing self-other representation, and 3) used tasks that involved social interactions requiring ToM (e.g., cooperation, exclusion).

Across the studies explored below, evidence suggests that alterations in brain regions associated with social cognition (superior temporal sulcus [STS], temporoparietal junction [TPJ]) are prevalent in BPD. Failures in ToM in BPD are also associated with problems developing a stable sense of self [60]; altered neural processing in regions associated with self-referential processing (medial prefrontal cortex [PFC]) have been found, providing neural evidence for this clinical phenomenon. Lastly, studies explicitly eliciting behavior in complicated social interactions (e.g., cooperation, exclusion) seem to suggest a combination of altered processing in regions associated with understanding other people's intentions as well as self-referential processing. Taken together, these studies suggest a network of brain regions underlying the clinical phenomena associated with failures in ToM in BPD.

Developing tasks that can be administered during fMRI to capture the subtle components of ToM can be challenging and has involved creativity in task construction [61]. In a study examining the neural correlates of cognitive empathy in a dimensionally assessed sample of BPD, participants completed an emotional-perspective taking task, while undergoing fMRI. During this task, participants were asked to determine which of two emotional faces displayed belonged in a portrayed social interaction, in which one of the individuals in the interaction had a blanked out face. Prior use of this task has shown it to be effective at activating brain regions associated with cognitive empathy. In this study, Haas and Miller [62] found that higher BPD trait scores were associated with hypoactivation in the superior temporal sulcus (STS) and the temporoparietal junction (TPJ). Both the STS and TPJ have long been understood to play central roles in ToM, and in particular, developing a working understanding of other people's intentions $[61,63]$. The STS is a central neural hub for social cognition processing, key for understanding other's actions and intentions, as well as perceiving human faces and motion [64].

Positing that ToM could be sub-divided into multiple components, Mier et al. [49] administered a task to a sample of individuals with BPD and HCs to assess different aspects of ToM: 1) neutral face processing, 2) emotion recognition, and 3) understanding emotional intent. In this task, participants were shown a statement about an emotional intention, an emotional state, or a physical feature of a depicted person [65]. Next, participants were shown emotional (angry, joyous, fearful) face stimuli (during the affective runs of the task), or neutral face stimuli (during the neutral face-processing runs of the task). Participants were asked to select whether the presented statements matched the picture displayed. Though this study did not find behavioral group differences during task performance, the researchers found relative hypoactivation in the BPD group in areas of the mirror neuron system (MNS; BA44) across all levels of the task, and hypoactivation in the right STS during the portion of the task in which participants had to correctly recognize the emotional intention. Mirror neurons, which are hypothesized to be part of the visuomotor system, simulate one's own motor representation, when witnessing other people conduct actions and are important for understanding the movement actions of others [66, 67]. The MNS provides humans a key tool for understanding and relating to the behavior of other people. Failure to accurately model and represent other people's behaviors may help explain functional difficulties in BPD [68].

Dziobek and colleagues [69] assessed empathy in a sample of BPD. They defined empathy as consisting of two components: cognitive empathy (largely synonymous with ToM), and emotional empathy, which involves having an appropriate emotional reaction to other people (and is more akin to emotion regulation, which will be discussed below in the current review). Participants in this study completed the Multifaceted Empathy Test (MET) [70]. In this task, participants were shown emotionally charged photographs of people in various situations. Participants were first asked to infer the mental states of the depicted individuals, to assess a participant's level of cognitive empathy (ToM). Next participants were asked to rate 'How much are you feeling for the person?' to tap into the construct of emotional empathy, or the degree that a person is able to feel the appropriate emotional reaction for another person [71]. During the cognitive empathy task trials, the researchers found greater 
changes in BOLD signal in the STS and superior temporal gyrus (STG) in the HCs relative to the BPD group. Within the BPD group, activation in this region was negatively correlated with intrusive memories; that is, increased activation in this region of interest (ROI) within the borderline group was associated with reduced intrusive symptoms. Intrusive memories are inherently inward-focused about an individual's previous life experiences. The reduced activation in the STS suggests that individuals who are high in intrusive memory symptoms are failing to activate a key brain regions associated with understanding and processing other people's behavior.

O'Neill and colleagues [72] examined neural functional connectivity during a ToM task in a sample of 17 individuals with BPD and $19 \mathrm{HCs}$. In the task, participants had to rate whether or not they understood or did not understand humorous cartoons and non-humorous pictures (consisting of an incongruity that could not be meaningfully interpreted). There were two types of humorous cartoons: 1) cartoons that consisted of visual puns and 2) cartoons that consisted of jokes that required mentalizing. Mentalizing humor relies on recognizing that one of the characters in the cartoon has a false belief. There is evidence that cartoons engaging ToM elicit increased activation in regions associated with ToM (e.g., TPJ, mPFC) [73]. The researchers examined functional coupling during the time course of the mentalizing trials using the subgenual ACC as a seed region (for an emotion brain network), which has shown altered activation in BPD in other studies $[70,74]$. During the ToM condition, O'Neill and colleagues found decreased functional connectivity in the participants with BPD relative to the $\mathrm{HCs}$ between the $\mathrm{ACC}$ and the left STS, right mid-cingulate cortex, and right TPJ. Previous research has suggested that the right TPJ, in particular, is involved in tasks associated with mentalizing [ 63 , $75,76]$. The decreased coupling of ToM brain regions and the affective brain region (seeded by the ACC) suggests that there is reduced engagement and modulation from affective regions during ToM tasks. The authors argue that this dysconnectivity may support the affective dysregulation which is common during ToM in BPD. It is possible that such dysconnectivity may also explain the phenomenon of hypermentalizing, in which individuals with BPD over-interpret and emotionally engage with the thoughts and beliefs of others.

In addition to impacting interpersonal relationships, failures in ToM are understood to relate to difficulties that individuals with BPD have developing a stable sense of self, leading to identity disturbances and self-loathing [77]. These difficulties comprise one of the symptom criteria, found in section II of DSM-5: "Identity disturbance: markedly and persistently unstable self-image or sense of self [12]." To test the neural correlates of this clinical phenomenon, Beeney and colleagues [78] conducted a study examining self-report measures of self-representation with an fMRI task designed to tap into self- and other-reflection. In the task, participants were 1) asked to evaluate themselves on a certain trait,2) asked how a close friend would evaluate them on that trait, and 3) asked how that close friend would evaluate themselves on the trait. Individuals with BPD showed altered neural activation, relative to the $\mathrm{HCs}$, across all three conditions of the task, regardless of whether they were evaluating themselves or imagining a friend doing the evaluating. The researchers found hyperactivation in the BPD group in the $\mathrm{mPFC}$, TPJ, rostral and dorsal anterior cingulate cortex (rACC and $\mathrm{dACC}$ ) and precuneus. Greater activation in these regions was mediated by poorer consistency on self-other representation (as measured by personality self-report). Interestingly, when thinking and evaluating themselves, the participants with BPD show increased activation in the TPJ, a key region for understanding other people's actions. This finding is in line with a recent study, which found greater activation in the TPJ and $\mathrm{mPFC}$ in individuals with high (compared to low) social anxiety, when they were instructed to direct their attention inward [79]. Increased self-focused attention in social anxiety is correlated with negative self-evaluation, anxiety, and arousal [80].

Finally, two studies assessed neural correlates of behavioral outcomes that likely result from failures of ToM in BPD, using tasks that simulated social interactions. Using an approach from game theory, one study examined individuals with BPD during interpersonal interactions in which the goal was to maintain cooperative relationships with another person [81]. Participants were instructed to conduct investments in a dyadic relationship, where one person was the investor (a HC) and the other was the trustee (either a $\mathrm{HC}$ or a participant with BPD). In order to maintain a cooperative relationship, the trustee was expected to repay the investor at least as much as they had invested (if the money had profited). The study found that the trustees with BPD struggled to maintain cooperation with their investor (that is, they would not return the requisite sum of money necessary to maintain a working relationship). When cooperation broke down, the trustees with BPD were unable to repair the relationship through coaxing, an effective method of regaining cooperation (by making increasingly more generous offers). In addition to the behavioral differences, this study also found reduced activation in the bilateral anterior insula when individuals with BPD were receiving small offers from their partners relative to the trustees that were HCs. The authors note the important role that insula plays in encoding and responding to social norm violations, perhaps due to its role in processing affective states such as disgust and guilt [82, 83]. These findings suggest that individuals with BPD have an inability to model and predict the interpersonal behaviors of their social partners, which inhibits their ability to build and maintain cooperative relationships.

In another study, researchers used the "Cyberball" task to simulate social exclusion in $\mathrm{BPD}$, in order to examine the neural correlates of this socially distressing phenomenon. In this task, subjects play a ball toss game with two virtual players. In the version of the task used by Domsalla and colleagues [84], there were three conditions: an exclusion condition, in which the subject was purposely ostracized and not passed the ball; an inclusion condition, in which each player received the ball an equal number of times; and a control condition, in which ball passing and the order of passing was determined based on a preset rule, and therefore could not be attributed to the intentions of the other players. Behaviorally, the researchers found that individuals with BPD experienced higher levels of self-reported exclusion relative to the $\mathrm{HCs}$, during both the inclusion and control conditions. On a neural level, the researchers found: higher activation in the $\mathrm{dACC}$ across all 
conditions in the BPD group relative to the HCs; higher activation in the middle temporal gyrus (MTG) and insula in $\mathrm{BPD}$ relative to $\mathrm{HCs}$ during the exclusion condition; higher activation in the precuneus and dorsomedial PFC (dmPFC) during inclusion. These findings suggest not only increased sensitivity to exclusion, but also an inability to identify when exclusion is actually occurring. Furthermore, higher activation in the $\mathrm{mPFC}$ and precuneus during inclusion highlight the increased activation in regions associated with self-referential processing in BPD, even in situations where the intention of the other person is to be inclusive.

Taken together, the findings from the ToM literature in BPD present evidence of alterations across a set of brain regions comprising a brain network involved in the tasks of understanding and relating to oneself and to others. Certain of the regions (e.g., mPFC, precuneous) found to have different patterns of activation in the BPD group relative to $\mathrm{HCs}$ are key nodes in the default mode network (DMN; See Figure 1), the network of brain regions understood to engage in stimulusindependent thought about one's past and future, and other people's minds $[85,86]$. Additionally, regions showing altered activation, such as the STS and TPJ, are understood to provide important inputs to the DMN about representations of other people's actions and intentions [87-89]. Mitchell and colleagues [90] argue that people often use knowledge of themselves to understand other people, explaining findings showing a role for the $\mathrm{mPFC}$ in both self-referential and mentalizing processes. Additional evidence suggests that the $\mathrm{mPFC}$ plays an equally important role in understanding others as understanding the self [91].

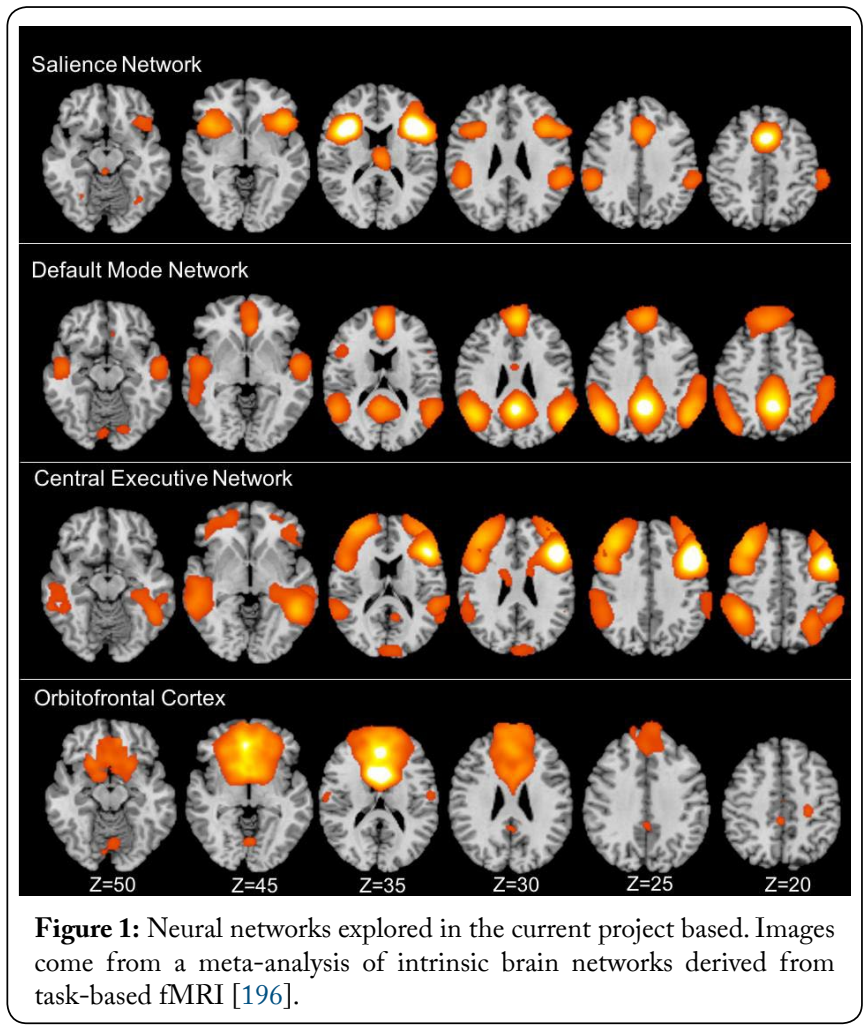

Legrand and Ruby [91] provide evidence for an even broader neural network (which they refer to as the
E-Network), involved in self-relatedness, and including the mPFC, precuneous, TPJ, and temporal poles. Suggestion of such a network provides a unifying framework for many of the brain regions which show alterations in both self- and-other processing in BPD. These findings possibly point to a shared vulnerability for two symptoms of BPD (unstable sense of self, unstable interpersonal relationships). Evidence from the BPD literature suggests that other symptoms, such as dissociation, may also be related to functional connectivity in the DMN $[92,93]$. These findings suggest that further exploring these networks (e.g., the DMN, MNS, or E-network) may provide novel avenues for understanding multiple symptoms in BPD. Additionally, the finding from O'Neill and colleagues, suggests that ToM-related brain activation may be negatively correlated with brain activation in regions associated with emotion processing and regulation (e.g., the ACC). As such, understanding the interplay between the ToM brain regions (STS, TPJ) and networks, such as the DMN, with brain networks primarily involved in emotion processes, may provide a meaningful inter-network connectivity worth exploring further in BPD symptomatology.

\section{Emotion Sensitivity and Recognition in BPD}

Emotion sensitivity refers to the threshold at which a person is able to detect emotional stimuli, while emotion recognition refers to the ability to accurately identify the emotion of detected emotional stimuli $[94,95]$. As some of the aforementioned studies on ToM have suggested [49], emotion sensitivity and recognition are often studied as a part of, or in tandem with, studies of ToM. But in the context of BPD, in which altered emotional processing plays such a prominent role in the clinical presentation of the disorder, emotion sensitivity and recognition are typically studied and assessed as separate constructs from ToM. The ability to correctly identify the emotions of others is necessary to guide appropriate behavioral responses. In BPD, failure to accurately interpret one's own, as well as other people's emotions (manifested as the clinical phenomenon known as alexithymia), appears to play a prominent role in impaired social functioning (and emotion dysregulation) [96].

While they are seemingly overlapping constructs, emotion sensitivity and recognition are conceptually different than emotion dysregulation, which is widely characterized as central to BPD pathology. Emotion sensitivity and recognition are more basic cognitive processes that serve as a necessary building blocks for appropriate social interactions and for developing the capacity to regulate emotions [97]. Emotion regulation, on the other hand, for the sake of this project, refers specifically to the various methods and strategies that people use to modulate their emotion experience $[98,99]$.

Behavioral studies of BPD have found evidence for impaired emotion sensitivity/recognition. A series of studies have identified group differences in accuracy in identifying emotions between individuals with BPD and HCs, though the results have been contradictory [95]. Some studies have found that individuals with BPD more accurately recognize emotions (or can correctly identify an emotion sooner) relative to $\mathrm{HCs}$ $[100,101]$ whereas other studies have found that individuals 
with BPD have impaired ability to identify emotions, relative to $\mathrm{HCs}[102,103]$. Wagner and Linehan [101] found that individuals with BPD, when asked to verbally identify an emotion (vs. select from options), were more accurate at identifying fear emotions and showed a bias of identifying fear emotions even when the emotion was neutral.

\section{Neural Networks, Emotion Recognition \& Sensitivity, and BPD}

Despite the contradictory behavioral findings, by far the largest body of functional, task-based neuroimaging literature on BPD has used tasks designed to tap into features of emotion sensitivity. Recent years have seen multiple review papers [29, $95,104]$ and a meta-analysis on this topic [74]. For the current project, we examine the findings from the recent reviews of emotion sensitivity. In addition, we include an analysis of additional fMRI studies on emotional sensitivity, which were not included in these previous reviews.

Van Zutphen and colleagues [104] conducted a review of emotion sensitivity, regulation, and impulsivity in BPD. In their exploration of emotion sensitivity, they identified ten studies explicitly exploring emotion sensitivity, using two types of stimuli: emotional faces and emotional scenes. They additionally identified one study on emotion recognition, which will be interpreted separately, below. The two studies that use emotional facial expressions as the stimuli, found increased amygdala and anterior cingulate cortex (ACC) activity in the BPD samples relative to $\mathrm{HCs}[105,106]$. Both of these studies used region of interest (ROI) approaches for the amygdala, and Minzenberg et al. [106] used an ROI approach for the ACC as well. As such, these studies confirmed their $a$ priori hypothesis about increased amygdala activation in BPD during emotion processing.

In a similar set of studies, Cullen and colleagues [107, 108] used a task in which participants saw emotional faces masked (that is, the emotion was displayed so quickly as to be imperceptible) and overt (where the participants could consciously perceive the emotional stimuli). They found increased amygdala activation during passive, overt emotional face viewing, but not when the faces were masked. Cullen et al. [108] used a method for assessing task-based functional connectivity called psychophysiological interactions (PPI), in order to determine whether there were group differences in amygdala patterns of co-activation with other brain regions over the course of the task. They found increased functional connectivity between the amygdala and the rostral ACC during overt fear processing and increased amygdalasubcortical connectivity during masked fear processing. These findings suggest that there may be different pathways for emotion processing depending on whether or not the stimuli are consciously perceived. To date, fewer studies of BPD have reported on task-based functional connectivity. This adds important information about potentially meaningful differences not only in task-based brain activation, but also in the ways that brain regions co-activate and modulate each other over the course of psychological processes.
Van Zutphen and colleagues [104] identified eight studies which used tasks in which the stimuli were emotional scenes. They found increased amygdala activation in four of the studies and increased insula activation in two of the studies. Findings for the ACC were mixed, with some studies reporting increased ACC activation in the BPD samples to emotional scenes and other studies finding reduced ACC activation to emotional scenes $[109,110]$. The amygdala, ACC, and insula, are understood to be key neural nodes for emotion processing $[111,112]$. Across the studies included (emotional scenes and faces), Van Zutphen and colleagues [104] determined that the most consistent finding was of increased amygdala activation in the BPD groups relative to HCs.

Additionally, Van Zutphen et al. [104] identified a broader network of regions showing altered activation during emotion processing in BPD. Three studies found decreased activation in regions hypothesized to be involved in emotion regulation and cognitive control, including the ventrolateral prefrontal cortex (vlPFC), dorsolateral prefontal cortex (dlPFC), ACC, and dorsomedial prefrontal cortex (dmPFC) [109, 110, 113]. These findings suggest that, despite using tasks designed to access emotion sensitivity, activation associated with emotion regulation is likely seen as well. This highlights the difficulty of trying to study many of these overlapping constructs, particularly given the relatively low temporal resolution of fMRI, which makes it difficult to separate out processes that may be happening rapidly in succession [114].

To our knowledge, only one study has explicitly examined brain activation associated with explicit emotion recognition during $\mathrm{fMRI}$ in BPD. In a small sample $(\mathrm{N}=10)$ of individuals with BPD, Guitart-Masip and colleagues [115] compared emotion discrimination to a same-sized sample of HCs. Participants were instructed to identify which of two displayed faces expressed an emotion (where one of the faces displayed was neutral). The researchers found that behaviorally, the patients with BPD were less accurate at discriminating negative faces, particularly disgust and fear, and they showed higher posterior temporal cortex activation than HCs. The researchers did not find group differences in amygdala activation. Hyperactivation in the temporal cortex in BPD seems to contradict the earlier studies of ToM (which generally found relatively decreased activation in this region in BPD). It may be that, when asked to explicitly distinguish between two emotions, individuals with BPD compensate more in the face of a greater challenge, and therefore we see increased temporal activation. However, conclusions are limited given the small sample size of the study. More studies are needed to better characterize brain activation during emotion recognition in this population, given the potential impact that errors in recognition may have on social interactions.

Ruocco and colleagues [74] conducted a meta-analysis of fMRI studies in BPD which contrasted negative emotion processing compared to neutral emotion processing. They utilized a coordinate-based meta-analytic method called activation likelihood estimation (ALE), which aims to determine commonly activated regions across a wide number of studies [116, 117]. In the context of fMRI research in $\mathrm{BPD}$, this method is particularly valuable because it can help 
overcome the ubiquitously small sample sizes, and therefore low reliability of findings, in this research area [118]. By pooling data across multiple samples, it is possible to identify robust findings that are consistently activated across studies (and among larger numbers of participants). Ruocco and colleagues found increased activation in the BPD subjects in the insula, inferior frontal gyrus (IFG), and posterior cingulate, during negative emotion processing and reduced activation in the dlPFC, subgenual and dorsal ACC, amygdala, and superior temporal gyrus, relative to $\mathrm{HCs}$.

The insula plays an important role in translating interoceptive information into the experience of emotions, especially disgust [119, 120]. Additionally, the insula is considered the hub of the salience network (SN; See Figure 1) along with the dACC, amygdala, ventral striatum, and substantia nigra/ventral tegmental area. The primary job of the salience network is to detect and determine salient information from bottom-up processes (e.g., the limbic system) and communicate with regions involved in top-down control [121, 122]. It has been suggested that, by attributing emotional importance to a greater number of stimuli, hyperactivation of the SN may play an important role in anxiety and neuroticism [36].

Reduced activation in the BPD group relative to the HCs in the vlPFC and dlPFC (found in both the metaanalysis by Ruocco and colleagues and the review by van Zutphen and colleagues) may indicate reduced involvement of the central executive network (CEN; See Figure 1). The CEN (also known as the left and right lateralized frontoparietal networks), anchored in the dlPFC and posterior parietal cortex and including the dorsomedial frontal/presupplementary motor area and vlPFC, is involved in cognitive control during demanding tasks, manipulating information in working memory, and behavioral regulation [122, 123]. It is believed that the CEN network operates behaviorally on identified salience, weighing choices for high level decision making, response selection, and response suppression. These findings suggest a heightened regulatory response to emotions in HCs, even in the absence of an explicit emotion regulation probe. This suggests that automatic emotion regulation upon processing emotional stimuli may be more readily accessible in $\mathrm{HCs}$.

A surprising finding in the meta-analysis by Ruocco is reduced amygdala activation across BPD studies, relative to HCs. van Zutphen and colleagues [104] highlighted the inconsistencies in the findings about the amygdala, as well, noting that some studies found that individuals with BPD have increased amygdala activation during emotion processing, whereas others found reduced amygdala activation. Both research groups noted the difficulty of scanning the amygdala using fMRI, given its proneness to signal dropout and image distortion (because of its location in the brain) [124]. Other potential sources of these inconsistent findings have been suggested, including differences in habituation to emotional stimuli, which have been noted in individuals with BPD $[125,126]$. Differences in amygdala habituation to fearful stimuli may be a more reliable neural marker than amygdala activation, which may be more variable across an entire task $[127,128]$.van Zutphen additionally argues that differences in levels of dissociation in individuals with BPD, which is often not assessed in fMRI studies using emotion processing tasks, may account for differences in amygdala activation - that is, dissociation may disrupt emotion processing and amygdala activation [129]. These findings, therefore, suggest that more research is necessary to clarify the role of the amygdala and to better explain the inconsistency in results. Yet beyond the amygdala, which has received the bulk of attention in the fMRI and BPD literature, other regions and networks (e.g., the insula as part of the $\mathrm{SN}$, the $\mathrm{CEN}$ ), may be broader neural systems deserving greater attention for studying emotion processing in BPD.

\section{Behavioral Dysregulation and Impulsivity}

Behavioral impulsivity is explicitly found in DSM-5 Section II of BPD criterion 4: "Impulsivity in at least two areas that are potentially self-damaging (e.g., spending, sex, substance abuse, reckless driving, binge eating) [12], but it is also associated with criterion 5, "recurrent suicidal behavior, gestures, or threats, or self-mutilating behavior" [12]. Impulsivity is considered a core feature of BPD [130] and is associated with a more severe course of the disorder and higher rates of suicidal behavior [2].

Many of the behaviors (e.g., substance use, sexual impulsivity) that individuals with BPD engage in are risky and dangerous [131]; as such, behavioral impulsivity often becomes the number one priority in treatment. In dialectical behavioral therapy (DBT), for example, treatment of lifethreatening behaviors (suicide and self-harm) precedes other treatment goals [132]. Additionally, impulsive behaviors have been shown to be the strongest predictor of BPD after 7 -years of follow-up [133]. Recent years have seen a growth in neuroimaging studies investigating neural correlates of impulsivity in BPD, in order to gain a better understanding of the biological underpinnings of this feature of the disorder.

Still, though impulsivity is conceptualized as a discrete symptom domain in BPD, some researchers argue that impulsivity in BPD stems from emotion dysregulation, which better characterizes the disorder [134]. Evidence supports this argument, with studies finding that while individuals with BPD endorse higher levels of impulsivity as measured by self-report, laboratory measures have yielded inconsistent and weak findings for impulsivity in emotionally neutral situations $[135,136]$. From this viewpoint, impulsive behaviors may be understood as maladaptive emotion regulation strategies [137, 138] but not as a discrete dimension of the pathology.

Other studies provide evidence for the dissociation of emotion dysregulation and behavioral impulsivity in the conceptualization of the disorder. Fossati and colleagues [139] found that features of impulsivity significantly predicted borderline traits, even after statistically partialling out facets of emotion dysregulation, as measured by the Difficulties in Emotion Regulation Scale [140]. Crowell and colleagues take a developmental psychopathology approach to conceptualizing BPD. From this standpoint, they highlight the different developmental etiologies and courses for impulsivity and 
emotion dysregulation, both of which ultimately contribute to BPD pathology [141]. They suggest that the behavioral component of emotion dysregulation is influenced by impulsivity, independent of emotion, and that high levels of trait impulsivity (and not emotion dysregulation) partially explains the overlap between BPD and other disorders of impulse control.

Researchers have found similarities between behavioral impulsivity (as measured by tasks) and trait impulsivity (measured through self-report) seen in BPD and in individuals with lesions in the orbitofrontal cortex (OFC) [142]. Damage to the OFC (See Figure 1) has been associated with socially inappropriate behavior, impulsivity, and emotional changes perhaps due to a bias toward immediate rewards [143, 144]. Berlin and colleagues [142] found that both individuals with BPD and those with OFC lesions differed significantly from $\mathrm{HCs}$ on performance in an impulsivity task and self-report measures. However, individuals with BPD were distinguished from those with OFC lesions by reporting higher subjective emotion and by a distinct personality profile (high neuroticism and introversion, low conscientiousness). Berlin and colleagues hypothesized that these differences between individuals with BPD and those with OFC lesions might be related to alterations in an additional neural circuit, associated with emotion processing, in individuals with BPD. Taken together, these studies suggest that impulsivity and emotion dysregulation are related, but nonetheless distinct, domains of BPD.

\section{Neural Networks, Impulsivity, and BPD}

Impulsivity is considered a multi-faceted construct [145]. As a result, a range of tasks are typically used to elicit the neural correlates of aspects of impulsivity. Tasks include those measuring neural activation associated with reward processing, response inhibition, delay discounting, and risk-taking - all of which aim to tap into facets of impulsivity [146]. For the current study, we surveyed the literature for studies that measured these constructs in BPD. Papers selected explored reward processing, response inhibition, and the neural activation specifically associated with impulsive behavior (e.g. self-harm). Taken together, these studies, point toward altered OFC activation across a number of studies. The implications of this will be discussed below.

Altered reward processing is consistently implicated in impulsivity-related pathology. Research has suggested that alterations in associated neural circuitry may play an important role in the development of externalizing psychopathology [147, 148]. One study compared brain activation during a reward processing task between a mixed sample of individuals with BPD and antisocial personality disorder (ASPD) and a HC group [149]. Vollm and colleagues found that while participants in the $\mathrm{HC}$ group showed increased activation in the lateral and medial OFC during the gain and loss conditions of the task, participants in the personality disorder (PD) group only showed lateral OFC activation in the loss condition of the task. In the PD group, activation in the OFC was negatively correlated with impulsivity scores, as measured by on Behavioral Inhibition Scale [150] but this finding was not shown in the HC group. This study is limited by its small sample size $(n=8)$, which is further confounded by the inclusion of both BPD and ASPD patients, though evidence suggests shared features of impulsivity in both disorders [151, $152]$. As such, it should be interpreted cautiously and warrants replication.

While self-injury is believed to serve many functions in BPD, including relief of aversive inner states, self-punishment, and as a response to dissociation, it has additionally been viewed as a feature of behavioral impulsivity [153]. Kraus and colleagues [154] conducted an fMRI study in which participants listened to a script, read in the first person singular by a professional actor, describing a standardized stressful scenario followed by an act of self-harm. The situation involved five stages: 1) a neutral sequence, 2) a trigger situation, 3) emotional and cognitive reactions to the situation, 4) a self-injurious behavior, and 5) relaxation. The researchers found that individuals with BPD showed reduced activation of the OFC and increased activation in the dlPFC relative to $\mathrm{HCs}$ while imagining the emotional and cognitive reactions described in the script. During the portion of the script describing the self-injurious act, BPD patients showed decreased activation in the mid-cingulate, relative to the HCs. Evidence has suggested an important role for the OFC in response inhibition [155]. Failure to sufficiently activate this region during an emotionally stressful situation may help account for the subsequent impulsive behavior, such as selfharm, which is often seen in BPD. Still, given the nature of the task, it is important to recognize that other psychological processes (e.g., emotion processing and emotion regulation) were likely also engaged as subjects listened to the scripted situation of a stressful event followed by self-harm.

In order to directly assess the potential role that failures in response inhibition may play in BPD, Wingenfeld and colleagues [156] administered the emotional Stroop task and compared performance on the task between a sample of 20 individuals with $\mathrm{BPD}$ and $20 \mathrm{HCs}$ while they underwent fMRI. In the emotional Stroop task, 12 words are presented (4 of each type: neutral, generally negative words, negative words specific to each participant, meaningless sequence of letters) in four colors and the participant has to correctly name the color that the word (or letters) is presented in. Stroop tasks require overcoming the prepotent response to read the word in order to say the color of the word. The emotional Stroop task was specifically developed to assess inhibition of interference related to emotional content. The $\mathrm{HCs}$ showed increased activation in the left ACC, right middle frontal gyrus (MFG), and right precentral gyrus during general negative compared to neutral words. Additionally, the HCs showed increased activation in left postcentral gyrus and IFG, right middle and superior temporal gyrus, right MFG, and left ACC during the individual (personally-relevant) negative compared to neutral words. The dorsal ACC has been shown to play a central role in regulation and inhibition during Stroop tasks [157]; failures to activate this region during emotional interference suggest difficulties in BPD patients to direct attention away from emotionally laden distracting information. A recent study 
examining BOLD differences between BPD and HCs during response inhibition in an emotionally neutral task failed to find group differences [158]. van Eijk and colleagues interpreted these findings to mean that failures in response inhibition are seen in emotionally laden contexts, but not during emotionally neutral conditions.

Silbersweig and colleagues [159] used a linguistic go/ no-go task, assessing motor inhibition, and compared neural activity between a sample of 16 patients with BPD and 14 HCs. During the task, participants were instructed to press a button after reading a word that was presented in normal font (go trial) and inhibit a button press after reading a word that appeared on the screen in italic font (no-go trial). Words used were evenly split between positive, negative, and neutral words. During the negative task conditions, the authors found reduced activation in the medial OFC in the BPD sample relative to the $\mathrm{HCs}$ whereas they found increased activity in the BPD sample in the lateral OFC. Additionally, they found increased amygdala, hippocampal and parahippocampal activation in the BPD sample and reduced activity in the subgenual ACC. Reduced ability to inhibit and restrain impulse expression (as measured by negatively coded trait constraint from the Multidimensional Personality Questionnaire [MPQ]) was negatively correlated with activation in the region of the medial OFC that had showed between-group activation differences. Given the emotional content of the task, the finding of increased activation of the limbic system is in line with previous studies, which have shown increased amygdala activation to negative stimuli in BPD.

Additionally, this study found a dissociation of the lateral and medial OFC, with increased activation in the lateral OFC and reduced activation in the medial OFC in the BPD group. Research using animal models of OFC lesions suggests a dissociable role of the medial and lateral OFC, where lateral OFC lesions were associated with increased impulsive choice in rats during delayed discounting whereas medial OFC lesions were associated with decreased impulsive choices. The authors argue that the medial OFC plays an important role in mediating behavioral responses to internal states whereas the lateral OFC mediates behaviors in response to sensory evaluation [160]. Silbersweig and colleagues hypothesize that an imbalance between activation in the two regions of the OFC may, in part, explain the behavioral dyscontrol in this population.

Jacob and colleagues [161] administered a similar go/ no-go task three separate times, with the task preceded each time by the reading of an emotion induction story (anger, joy, neutral mood). During the go/no-go task, the participants had to press a button for every letter that appeared on the screen, except for the letter "X." The sample consisted of 17 women with BPD and $18 \mathrm{HCs}$. The authors found no group differences in behavior during the tasks, but found reduced activation in the patient group in the inferior frontal cortex (IFC) during the go/no-go task following the anger induction. The IFC, elsewhere in this report referred to as the vIPFC, is uniquely involved in cognitive suppression of responses and set-switching [162]. Motor impulsivity, as assessed by the go/no-go task, is an important dimension of impulsivity, reflecting failure to inhibit a pre-potent response [163]. Motor impulsivity, akin to perseverance and acting on the spur of the moment [145], has been shown to be related to BPD pathology [130]. Further research is necessary to determine to what degree motor impulsivity may relate to behavioral impulsivity seen in BPD, particularly during emotion dysregulation.

Given the frequent use of emotional stimuli across many of the fMRI studies of impulsivity, it remains difficult to parse out whether there are neural markers of impulsivity in the absence of emotional content. Among the few studies that have assessed aspects of impulsivity in the absence of emotional stimuli, the fMRI evidence is mixed; Vollm and colleagues found neural differences in individuals with BPD during reward processing in the absence of emotional content, whereas van Eijk and colleagues [158] found no group differences in neural activation during response inhibition, when the task did not involve an emotional component. Reward processing and response inhibition reflect very different dimensions of the multidimensional construct of impulsivity [164, 145]. Therefore, comparing the findings from these studies is difficult. Given the ongoing debate about the differential role of impulsivity in BPD (relative to emotion dysregulation), this review suggests that more fMRI research is needed on impulsivity in BPD, to probe the neural correlates of impulsivity in the absence of emotional content. Additionally, more $\mathrm{fMRI}$ research could clarify whether altered patterns of brain activation are seen across the dimensions of impulsivity, or in specific domains of impulsivity.

Despite these limitations, the results of multiple fMRI studies accessing components of impulsivity in BPD suggest that the OFC may be consistently under-activated relative to HCs during tasks that require inhibition or impulse control in this population. The $\mathrm{OFC}$ is a large brain area that encompasses parts of the ventrolateral and ventromedial frontal cortex and is involved in numerous neural circuits (e.g., reward, inhibitory control, motivation) with connections to many brain regions, including the amygdala, hippocampus, $\mathrm{mPFC}$, insula, and striatal regions [165]. The OFC is understood to play an important role in motivation, learning, response inhibition, and decision-making. In particular, neuroimaging studies have found that reward valuation and reinforcers are encoded in the OFC, in a circuit involving the amygdala [166, 167]. Altered OFC activation has been implicated across impulsivity related disorders/behaviors, including substance use, ADHD, obesity, and pathological gambling [165, 168170]. The findings from the studies included in the current review suggest that a similar circuitry is altered in BPD, highlighting the potential independence of the impulsivity domain (from emotion dysregulation) in BPD pathology. The findings from Silbersweig et al. [159], though, suggest that there may be important sub-divisions within the OFC that might differentially relate to impulsivity symptoms in BPD.

In addition, these studies find altered activation in regions that are known to be involved in the inhibitory control circuitry, such as the OFC, vlPFC, MFG, and ACC [171]. These cognitive control regions are implicated in response inhibition and performance monitoring. Additionally, this circuitry is understood to play an important role in emotion regulation 
both through attention deployment and cognitive change [34]. As such, it is clear that regions involved in impulsivity and emotion regulation overlap. Further research is necessary to clarify the distinct and overlapping neural circuitry of these features of the disorder as a way of potentially determining their relatedness as symptom domains.

\section{Emotion Dysregulation}

At the core of Marsha Linehan's biosocial theory of BPD, which has gained increasingly more attention and focus as a model for the etiology and treatment of BPD, is the notion that $\mathrm{BPD}$ is a disorder of emotion dysregulation (ED) [52, $141,172,173]$. ED is explicitly manifest in the clinical criteria in DSM-5: "Affective instability due to a marked reactivity of mood (e.g., intense episodic dysphoria, irritability, or anxiety) usually lasting a few hours and only rarely more than a few days" and "inappropriate, intense anger or difficulty controlling anger (e.g., frequent displays of temper, constant anger, recurrent physical fights)" [12]. Additionally, other symptoms such as suicidality and self-harm, as well as impulsivity (as discussed above) and unstable interpersonal relationships are understood to be highly related to ED.

The widespread acceptance of the centrality of ED is evident in the recent introduction of a research journal entitled Borderline Personality Disorder and Emotion Dysregulation. DBT, which has been developed, researched, and popularly accepted as the gold-standard treatment for BPD, operates from a biosocial framework in which ED is understood to be at the heart of the pathology [174]. In the biosocial theory, ED results from an interactive process between biological vulnerabilities and environmental influences, which are characterized as invalidating $[141,52]$. This theory posits that emotion sensitivity, explored above, serves as a temperamental precursor, placing certain people at risk for the extreme ED associated with BPD pathology.

ED has been defined by Gratz and Roemer [140] as a multi-dimensional construct consisting of six aspects: 1) nonacceptance of emotion responses, 2) difficulties engaging in goal-directed behavior, 3) impulse control difficulties, 4) lack of emotional awareness, 5) limited access to emotion regulation strategies, and 6) lack of emotional clarity. Gratz and Tull [175] posit that ED refers to the failure to respond effectively to negative emotions, not the inherent experience of having negative emotions. The model does not assess the quality of the emotional experience (e.g., intensity), but rather the response to emotional experiences. Additionally, Gratz and Tull argue that ED does not refer to emotional vulnerability. That is, an individual can have intense or reactive emotional responses to stimuli, without being dysregulated. Research on $\mathrm{ED}$ and $\mathrm{BPD}$ has found evidence for particular aspects of the multidimensional construct (e.g., unwillingness to experience emotional distress in order to pursue goal directed behavior, failure to use regulation strategies, impulse control difficulties) to be meaningfully associated with BPD pathology [173, 176]. As can be seen from this framework, impulse control difficulties are understood to be a feature of ED.

\section{Neural Networks, Emotion Dysregulation, and BPD}

Though much has been written about the role of emotion dysregulation in the etiology, course, and treatment of BPD, far fewer studies have used fMRI to examine the neural correlates of emotion regulation and dysregulation in BPD. This may, in part, result from the difficulty of developing tasks that specifically tap into emotion regulation processes, in the absence of more basic processing (e.g., sensitivity and recognition) [103]. For the current review, we found that the studies exploring the neural correlates of emotion regulation in BPD used paradigms in which participants were instructed to apply emotion regulation strategies to modulate an emotional reaction to a given stimulus.

In line with the model of ED presented by Gratz and Roemer [140], Schulze and colleagues [110] theorized that emotional difficulties in individuals with BPD stem from dissociable components of emotional reactivity and an inability to engage regulatory control over reactivity. In order to measure the neural correlates of regulatory control, Schulze and colleagues used a cognitive reappraisal paradigm in a sample of individuals with BPD and HCs while they underwent fMRI. During the task, participants were instructed to notice their emotional reactions while looking at emotionally charged pictures. Next three types of instructions appeared on the screen: 1) subjects were instructed to increase their emotion to the picture (by imagining that they, or a close relative, was involved in the scene); 2) subjects were instructed to decrease their emotional reaction to the scene (by imagining that the situation was not real); 3) subjects were instructed to maintain their reaction to the image, without trying to modulate their emotions. Subjects then spent 8-seconds using the suggested cognitive reappraisal strategy (all of which had been taught during a previous training session).

During the initial viewing phase for the negative images, the researchers found group differences in amygdala and insula activation, where the individuals with BPD showed enhanced activation in these regions. These regions map onto those highlighted above, in the discussion of emotion sensitivity, as key for processing emotional stimuli. During the regulation phase of the task, they found no group differences in amygdala activation. They found that patients with BPD showed increased activation in the bilateral insula and decreased activation in the OFC during down-regulation of negative emotions but no group differences during the trials instructing participants to increase their negative emotions. The OFC has important connections mediating prefrontal regions (e.g., dlPFC and vlPFC) and sub-cortical, limbic regions, such as the amygdala and as such is known to play an important role in emotion regulation [177]. In studies of cognitive change, the OFC has been found to be activated by appraisal of emotional stimuli (through evaluating the emotional value of a stimuli and then selecting actions) [34, 178]. Failure to activate this region, in conjunction with increased activation in the amygdala and insula, are in line with bottom-up/topdown emotion dysregulation models of BPD, which suggest increased emotional salience and sensitivity, coupled with a 
reduced capacity to activate prefrontal regions associated with cognitive control of emotional processes.

Using a similar task, Koenigsberg and colleagues [109] sought to assess neural correlates of emotion processing and emotion distancing, a cognitive reappraisal strategy in which the individual views a stimulus from the perspective of a detached observer. Participants were trained on the cognitive strategy of distancing, before the task began. The task was taken from previous studies examining down regulation of emotional processing [34]. During the task, participants looked at negative and neutral interpersonally based pictures and were instructed to either "suppress" their emotional reaction (and use the cognitive strategy of distancing) or to simply look at the images and respond naturally (with the instruction "maintain"). During the distancing condition, the HCs showed increased activation in the dACC and the bilateral intraparietal sulci (IPS). The BPD group showed greater activation in the STS, right superior frontal gyrus, and increased activation of the right amygdala relative to baseline and the passive looking condition, compared to the HCs.

The dACC plays an important role in appraisal of emotion and recent meta-analytic work has additionally highlighted the importance of this region in reappraisal of emotional stimuli [111]. Despite not finding behavioral differences between the groups in their affective ratings of the images during distancing, the fMRI results from Koenigsberg and colleagues [109] suggest that the HCs are nonetheless engaging brain regions known to be involved in reappraisal, a particularly effective regulatory strategy [179]. During distancing, the participants with BPD exhibited increased activation in brain regions associated with emotion generation and social cognition. These findings further the theory that $\mathrm{ED}$ in this population stems from hyperactivation in limbic regions coupled with reduced prefrontal activation in cognitive control regions. In this case, these findings emerge even when patients are specifically prompted to use regulatory strategies.

Given the prevalence of traumatic experiences in individuals with BPD, Lang and colleagues [180] conducted a study to determine the impact of traumatic experiences on cognitive reappraisal of emotion in BPD. They also examined differences in brain activation over the course of the task, as previous evidence has shown that activation in the PFC in healthy individuals during emotion regulation typically happens within the first seconds after the stimulus and then diminishes [181]. The researchers included three groups: nontraumatized women (HCs), trauma-exposed women without PTSD (non-PTSD), and trauma-exposed women (without PTSD) with BPD. Participants were read 6 scripts (three of which were negative, three were neutral) and were instructed to: increase ("enhance") their emotional reaction by imagining themselves as the central figure in the story; decrease their emotional reaction by imagining the contents of the script from a detached, third-person perspective ("distancing”); or respond to each script without trying to alter their emotions ("maintain").

Overall, Lang and colleagues [180] found increased early activations in the left $\mathrm{ACC}$, left medial and right dorsomedial $\mathrm{PFC}$, and posterior cingulate cortex in the $\mathrm{HC}$ group relative to the BPD and non-PTSD groups during up-regulation and a trend toward greater $\mathrm{ACC}$ activation relative to the $\mathrm{BPD}$ group during the early stage of down-regulation. The participants with BPD, though, showed early deactivation in the ACC and left medial PFC, and right precuneous during up-regulation and in the left middle temporal cortex during the late interval. During down-regulation, the BPD participants showed increased activation in the putamen and right middle and superior temporal gyri during the early phase and in the left middle and temporal gyrus during the late phase. Overall the researchers concluded that most of the emotion regulation processes occurred (across all three groups) during the early phase of the task, in supporting the idea that emotion regulation happens rapidly and briefly [181]. Of note, the non-PTSD and BPD samples were very similar to one another relative to the HCs. The researchers suggest that brain neural differences may be non-specific to BPD, but indicative of trauma more generally. This conclusion highlights an important caveat for most of the fMRI and BPD literature. Namely, that many factors -- including traumatic experiences but also treatment history, medication history, other psychiatric comorbidity - are difficult to control for within studies and even more difficult to account for across studies. As such, it is challenging to determine whether certain processes are specific to BPD, or to some other factor, such as trauma, which covaries with BPD.

Across these three studies, there is some evidence for limbic/SN hyperactivity and reduced activation in prefrontal regions, such as the $\mathrm{ACC}, \mathrm{OFC}, \mathrm{mPFC}$, known to be involved in regulatory strategies. As such, these findings support the most ubiquitous neural theory of BPD, in which deficits are understood to stem from bottom-up hyperactivity in emotion processing regions and reduced activation in top-down control regions [33]. Given the prominent understanding of BPD as an emotion regulation disorder [182], the prevalence of this neural profile is unsurprising.

The studies of emotion regulation in BPD reported in the current project use fMRI paradigms in which the participants are instructed to use emotion regulation strategies and differences in neural activation are assessed. Other types of tasks will likely be useful in further elucidating the neural underpinnings of this important construct in BPD. Additionally, as has been noted, it is very difficult to parse out the different neural pathways associated with emotion processing and emotion regulation given both the conceptual and temporal overlap. Studies using operant training through real-time fMRI based neuro-feedback have shown that individuals can use volitional control to modulate brain reactivity in emotion regions in HCs [183]. Future studies should consider incorporating novel tasks, or diversifying the fMRI paradigms, in order to better characterize the specific neural underpinnings of ED in BPD and how these may help explain this prominent feature of the disorder.

\section{Conclusions}

So where does this leave us? To argue that the psychological processes and symptom domains in BPD are 
discrete and unrelated to one another is patently not true. We know, based on common sense as well as a large body of research, that many of the processes of BPD are interrelated. It is readily apparent than an individual's sensitivity to emotion will likely impact their potential for emotion dysregulation, which certainly impacts their interpersonal relationships and their behavioral constraint. As has been highlighted, evidence suggests that emotion dysregulation may underlie behavioral impulsivity and interpersonal sensitivity [141, 134], yet we also find suggestive evidence that interpersonal sensitivity (and rejection sensitivity) may underlie many of the other BPD symptoms $[38,184]$. The goal of this project, therefore, was not to determine, what is, once and for all the chicken and what is the egg in the BPD diagnosis, because that is a futile endeavor.

Yet we also know that there is a wide variation in the clinical presentation of BPD, which partially explains the growing unease with the categorical, polythetic diagnostic model. This helps account for the increasing research of, and enthusiasm for, alternative conceptualizations of the pathology, including exploring sub-types of the disorder or a dimensional model for diagnosis. While there is growing acceptance that clinical heterogeneity is a reality for $\mathrm{BPD}$, less biological research has been brought to bear to support this claim. As a result, one of the primary goals of the current project was to review the task-based $\mathrm{fMRI}$ literature to determine if it could shed light on any of the nuances within the BPD diagnostic criteria. In doing so, we have identified specific brain regions and neural networks associated with symptom domains, in attempt to understand how neural differences across the domains can explain the differences in the clinical presentation.

But much as we know that the clinical symptoms of BPD do not occur independently, we also know that processes in the brain do not occur in isolation. Based on this review, it is plain to see that many of the same brain regions appear to play important roles in more than one symptom domain of BPD (e.g., the STS is altered in both ToM and emotion regulation tasks; OFC in emotion dysregulation and behavioral impulsivity). As we argue in this project, a networkbased approach, focusing on the broader circuits at play such as the DMN, SN, and CEN is an important direction for BPD neuroimaging research and may help overcome the limitations of such a piecemeal literature. A few studies have already begun this work and find compelling evidence for the role that altered activation in these networks (measured using rs-fMRI, while the brain is not performing a specific task and is therefore considered at rest) plays in BPD pathology [72, $92,185]$. Additionally, we know that these neural regions and networks interplay in complex patterns in order to execute the processes associated with affect, cognition, and behavior and altered interactions between networks and regions likely underlies pathology. Preliminary research in BPD using connectivity approaches suggest that the complex observable pathology may be related to the interplay between neural regions and networks $[29,107,126,186]$.

Overall, a central goal of this project is to highlight the diversity of neural networks involved in a diverse set of psychological processes in BPD. In doing so, we move beyond a simplistic story about bottom-up and top-down dysfunction. By moving away from this model, we gain a nuanced sense of why there is so much diversity in symptom presentation. Future research is going to require dissecting whether prominence in disengagement of the DMN, for example, predicts a different phenotypic expression relative to the over-engagement of the SN.

As reviewed earlier, there has been much discussion about the best way to conceptualize BPD. But this discussion has been occurring as part of a larger, ongoing conversation across the fields of psychiatry, psychology, and neuroscience about the potential value of taking a dimensional perspective to observable clinical phenomena. Recently, the National Institute of Mental Health (NIMH) moved away from the traditional DSM categories for studying psychopathology and now uses the Research Domain Criteria (RDoC) in order to structure the funding and implementation of psychopathology research. The central thrust of the $\mathrm{RDoC}$ approach is to better align psychopathological research with findings from clinical neuroscience and genetics $[187,188]$. One of the main tenets of the $\mathrm{RDoC}$ is that both neurobiological and observable clinical phenomena exist on dimensions, which may cut across multiple disorders. Additionally, $\mathrm{RDoC}$ highlights the importance of neural circuits, above and beyond individual brain regions, that underlie complex patterns of behavior, and even more complex co-occurrences of multiple disorders [189].

The current project aims to utilize the dimensional framework advocated by $\mathrm{RDoC}$ to both the underlying neural substrates as well as the clinical presentation of BPD. We believe that approaching the BPD diagnosis from a more dimensional, systems approach, can better align the research with current $\mathrm{RDoC}$ literature. For example, recent works suggests that emotion dysregulation, a key aspect of BPD, may also be a useful transdiagnostic marker of pathology, amenable to inclusion within the RDoC matrix [190]. Evidence also suggests that the neural networks reviewed in the current project (e.g., the DMN, SN, and CEN) play an important role in other, related forms of psychopathology, including PTSD [191-193]. Moving the conversation on BPD toward more dimensional models (both psychiatric and neuroscientific) will facilitate the transfer of knowledge from the broader fields of psychology, psychiatry, and neuroscience and will bring this research to bear on, and better elucidate, BPD.

There are limitations in this review. Notably, the findings are limited by the types of fMRI tasks employed. For example, given the debate in the field about whether or not impulsivity and $\mathrm{ED}$ can be understood as distinct aspects of BPD, the fact that so many of the tasks tapping into aspects of impulsivity incorporate emotional elements makes it difficult to weigh in on this question using fMRI. Additionally, given the prominence of ED to many theoretical frameworks of BPD, the limited number and type of fMRI tasks used to directly assess neural processes associated with BPD suggests that much more research needs to be done on this. As such, we believe that there is a need not only for more fMRI literature on BPD, but also better streamlining of the research questions. For example, if the nature of impulsivity and ED in BPD is being questioned and measured psychometrically, more studies 
using fMRI tasks appropriate for teasing this apart should be employed.

Additionally, even if it were entirely possible to disentangle related neural processes, it is near impossible to develop fMRI tasks that can truly access only specific elements of functioning. For example, as the studies reviewed show, it is hard to develop tasks to elicit brain activation associated with emotion regulation, without tapping into brain activation associated with emotion recognition and sensitivity - as these processes are ultimately happening nearly simultaneously. Current research modalities, using animal models and methods such as optogenetics, will be helpful for dissociating and better localizing aspects of these processes [194, 177]. Nonetheless, the lack of temporal resolution of fMRI continues to make this a challenging aspect of this research.

For the current project, we chose to examine the role that fMRI could play in elucidating the different neural underpinnings for the symptom domains of BPD. Future reviews should examine whether findings from other neuroimaging modalities (e.g., PET, MRI, EEG and restingstate fMRI [rs-fMRI]) support the conclusions drawn in the current project. Important work elucidating neural function and symptom domains of BPD has been done using PET. For example, a recent study found that regional brain metabolism in prefrontal regions was negatively correlated with selfreported hostility [28]. Similarly, using EEG, researchers have found that theta activity in individuals with BPD was correlated with dissociative experiences and pain ratings [195]. Future work would benefit from determining whether the findings converge across the neuroimaging modalities.

In the current project, we reviewed the research on taskbased functional neuroimaging using $\mathrm{fMRI}$ in an effort to elucidate the neurobiological substrates underlying the symptom domains of BPD. Such an approach is particularly useful for a disorder like BPD, in which there is widely reported variation in the clinical presentation of the disorder. As a result, clarifying the neural systems underlying the varied aspects of the disorder can be helpful in explaining this clinical heterogeneity. We believe that findings are suggestive of altered activity in a set of neural networks (notably the DMN, SN, and $\mathrm{CEN}$ ) and altered connectivity between networks (e.g., fronto-limbic connectivity, STS/TPJ and DMN connectivity) across the symptom domains. Future studies employing experimental designs with BPD patients, where the goal is to more fully investigate a neurobehavioral system such as one of the $\mathrm{RDoC}$ constructs at multiple levels of analysis, from network to symptom level, can help further clarify the BPD diagnosis as well as move BPD research more in line with the goals of the $\mathrm{RDoC}$ research matrix.

\section{References}

1. Skodol AE, Gunderson JG, McGlashan TH, Dyck IR, Stout RL, et al. 2002. Functional impairment in patients with schizotypal, borderline, avoidant, or obsessive-compulsive personality disorder. Am J Psychiatry 159(2): 276-283. doi: 10.1176/appi.ajp.159.2.276

2. Black DW, Blum N, Pfohl B, Hale N. 2004. Suicidal behavior in borderline personality disorder: prevalence, risk factors, prediction, and prevention. J Pers Disord 18(3): 226-239. doi: 10.1521/ pedi.18.3.226.35445
3. Goodman M, Roiff T, Oakes AH, Paris J. 2012. Suicidal risk and management in borderline personality disorder. Curr Psychiatry Rep 14(1): 79-85. doi: 10.1007/s11920-011-0249-4.

4. Paris J. 2002. Chronic suicidality among patients with borderline personality disorder. Psychiatr Serv 53(6): 738-742. doi: 10.1176/appi. ps.53.6.738

5. Sanislow CA, Grilo CM, Morey LC, Bender DS, Skodol AE, et al. 2002. Confirmatory factor analysis of DSM-IV criteria for borderline personality disorder: findings from the collaborative longitudinal personality disorders study. Am J Psychiatry 159(2): 284-290. doi: 10.1176/appi.ajp.159.2.284

6. Haaland V, Landro N. 2009. Pathological dissociation and neuropsychological functioning in borderline personality disorder. Acta Psychiatr Scand 119(5): 383-392. doi: 10.1111/j.16000447.2008.01323.x.

7. Zanarini MC, Gunderson JG, Frankenburg FR. 1990. Cognitive features of borderline personality disorder. Am J Psychiatry 147(1): 5763. doi: 10.1176/ajp.147.1.57

8. New AS, Goodman M, Triebwasser J, Siever LJ. 2008. Recent advances in the biological study of personality disorders. Psychiatr Clin North Am 31(3): 441-461, vii. doi: 10.1016/j.psc.2008.03.011

9. Skodol AE, Siever LJ, Livesley WJ, Gunderson JG, Pfohl B, et al. 2002. The borderline diagnosis II: biology, genetics, and clinical course. Biol Psychiatry 51(12): 951-963. doi: 10.1016/S0006-3223(02)01325-2

10. American Psychiatric Association. 1980. Diagnostic and statistical manual of mental disorders (3rd ed.). American Psychiatric Publishing, Washington, DC, USA.

11. American Psychiatric Association, 2000. Diagnostic and statistical manual of mental disorders (4th ed., text rev.). American Psychiatric Publishing, Washington, DC, USA.

12. American Psychiatric Association, 2013. Diagnostic and statistical manual of mental disorders (5th ed.). American Psychiatric Publishing, Arlington, VA, USA.

13. Miller JD, Morse JQ, Nolf KA, Stepp SD, Pilkonis PA. 2012. Can DSM-IV borderline personality disorder be diagnosed via dimensional personality traits? Implications for the DSM-5 personality disorder proposal. J Abnorm Psychol 121(4): 944-950. doi: 10.1037/a0027410

14. Samuel DB, Miller JD, Widiger TA, Lynam DR, Pilkonis PA, et al. 2012. Conceptual changes to the definition of borderline personality disorder proposed for DSM-5. J Abnorm Psychol 121(2): 467-476. doi: $10.1037 / \mathrm{a} 0025285$

15. Widiger TA, Trull TJ. 2007. Plate tectonics in the classification of personality disorder: shifting to a dimensional model. Am Psychol 62(2): 71-83. doi: 10.1037/0003-066X.62.2.71

16. Trull TJ, Distel MA, Carpenter RW. 2011. DSM-5 Borderline personality disorder: At the border between a dimensional and a categorical view. Curr Psychiatry Rep 13(1): 43-49. doi: 10.1007/ s11920-010-0170-2.

17. Krueger RF. 2005. Continuity of axes I and II: toward a unified model of personality, personality disorders, and clinical disorders. J Pers Disord 19(3): 233-261.

18. Digre E, Reece J, Johnson A, Thomas R. 2009. Treatment response in subtypes of borderline personality disorder. Personal Ment Health 3(1): 56-67. doi: 10.1002/pmh.64

19. Eurelings-Bontekoe EHM, Peen J, Noteboom A, Alkem, M, Dekker J. 2012. Differential treatment response of subtypes of patients with borderline personality organization, as assessed with theory-driven profiles of the Dutch short form of the MMPI: a naturalistic follow-up study. J Pers Assess 94(4): 380-392. doi: 10.1080/00223891.2012.674995

20. Nosè M, Cipriani A, Biancosino B, Grassi L, Barbui C. 2006. Efficacy of pharmacotherapy against core traits of borderline personality disorder: meta-analysis of randomized controlled trials. Int Clin Psychopharmacol 21(6): 345-353. doi: 10.1097/01.yic.0000224784.90911.66 
21. Ingenhoven TJ, Duivenvoorden HJ. 2011. Differential effectiveness of antipsychotics in borderline personality disorder: meta-analyses of placebo-controlled, randomized clinical trials on symptomatic outcome domains. J Clin Psychopharmacol 31(4): 489-496. doi: 10.1097/ JCP.0b013e3182217a69.

22. Hollander E, Swann AC, Coccaro EF, Jiang P, Smith TB. 2005. Impact of trait impulsivity and state aggression on divalproex versus placebo response in borderline personality disorder. Am J Psychiatry 162(3): 621624. doi: 10.1176/appi.ajp.162.3.621

23. Krueger RF, Derringer J, Markon KE, Watson D, Skodol AE. 2012. Initial construction of a maladaptive personality trait model and inventory for DSM-5. Psychol Med 42(9): 1879-1890. doi: 10.1017/ S0033291711002674

24. Lynam DR, Widiger TA. 2001. Using the five-factor model to represent the DSM-IV personality disorders: an expert consensus approach. $J$ Abnorm Psychol 110(3): 401-412. doi: 10.1037/0021-843X.110.3.401

25. Miller JD, Bagby RM, Pilkonis PA, Reynolds SK, Lynam DR. 2005. A simplified technique for scoring DSM-IV personality disorders with the Five-Factor Model. Assessment 12(4): 404-415. doi $10.1177 / 1073191105280987$

26. Morey LC, Benson KT, Skodol AE. 2016. Relating DSM-5 section III personality traits to section II personality disorder diagnoses. Psychol Med 46(3): 647-655. doi: 10.1017/S0033291715002226

27. Hallquist MN, Pilkonis PA. 2012. Refining the phenotype of borderline personality disorder: Diagnostic criteria and beyond. Personal Disord 3(3): 228-246. doi: 10.1037/a0027953

28. Charles Schulz S, Camchong J, Romine A, Schlesinger A, Kuskowski M, et al. 2013. An exploratory study of the relationship of symptom domains and diagnostic severity to PET scan imaging in borderline personality disorder. Psychiatry Res 214(2): 161-168. doi: 10.1016/j. pscychresns.2013.05.007

29. Krause-Utz A, Veer IM, Rombouts SARB, Bohus M, Schmahl C, et al. 2014. Amygdala and anterior cingulate resting-state functional connectivity in borderline personality disorder patients with a history of interpersonal trauma. Psychol Med 44(13): 2889-2901. doi: 10.1017/ S0033291714000324

30. Mauchnik J, Schmahl C. 2010. The latest neuroimaging findings in borderline personality disorder. Curr Psychiatry Rep 12(1): 46-55. doi: $10.1007 / \mathrm{s} 11920-009-0089-7$

31. Arthurs OJ, Boniface S. 2002. How well do we understand the neural origins of the fMRI BOLD signal? Trends Neurosci 25(1): 27-31. doi: 10.1016/S0166-2236(00)01995-0

32. Krause-Utz A, Winter D, Niedtfeld I, Schmahl C. 2014. The latest neuroimaging findings in borderline personality disorder. Curr Psychiatry Rep 16(3): 438. doi: 10.1007/s11920-014-0438-z

33. New AS, Hazlett EA, Buchsbaum MS, Goodman M, Mitelman SA, et al. 2007. Amygdala-prefrontal disconnection in borderline personality disorder. Neuropsychopharmacology 32(7): 1629-1640. doi: 10.1038/ sj.npp.1301283

34. Ochsner KN, Gross JJ. 2005. The cognitive control of emotion. Trends Cogn Sci 9(5): 242-249. doi: 10.1016/j.tics.2005.03.010

35. Ochsner KN, Silvers JA, Buhle JT. 2012. Functional imaging studies of emotion regulation: a synthetic review and evolving model of the cognitive control of emotion. Ann N Y Acad Sci 1251: E1-24. doi: 10.1111/j.1749-6632.2012.06751.x

36. Menon V. 2011. Large-scale brain networks and psychopathology: a unifying triple network model. Trends Cogn Sci 15(10): 483-506. doi: 10.1016/j.tics.2011.08.003

37. Mesulam MM. 1998. From sensation to cognition. Brain 121(pt 6): 1013-1052. doi: 10.1093/brain/121.6.1013

38. Gunderson JG, Lyons-Ruth K. 2008. BPD's interpersonal hypersensitivity phenotype: a gene-environment-developmental model. J Pers Disord 22(1): 22-41. doi: 10.1521/pedi.2008.22.1.22.BPD
39. Gunderson JG. 2007. Disturbed relationships as a phenotype for borderline personality disorder. Am J Psychiatry 164(11): 1637-1640. doi: 10.1176/appi.ajp.2007.07071125

40. Modestin J. 1987. Quality of interpersonal relationships: the most characteristic DSM-III BPD criterion. Compr Psychiatry 28(5): 397402. doi: 10.1016/0010-440X(87)90056-3

41. Aviram RB, Brodsky BS, Stanley B. 2006. Borderline personality disorder, stigma, and treatment implications. Harv Rev Psychiatry 14(5): 249-256. doi: 10.1080/10673220600975121

42. Kernberg O. 1967. Borderline personality organization. J Am Psychoanal Assoc 15(3): 641-685. doi: 10.1177/000306516701500309

43. Stern A. 1938. Psychoanalytic investigations of and therapy in the Border Line Group of Neuroses. Psychoanal Q 7: 467-489.

44. Hill J,Pilkonis P,Morse J, Feske U, Reynolds S, et al.2008. Social domain dysfunction and disorganization in borderline personality disorder. Psychol Med 38(1): 135-146. doi: 10.1017/S0033291707001626

45. Livesley WJ, Jang KL, Jackson DN, Vernon PA. 1993. Genetic and environmental contributions to dimensions of personality disorder. $\mathrm{Am}$ J Psychiatry 150(12): 1826-1831. doi: 10.1176/ajp.150.12.1826

46. Zanarini MC, Frankenburg FR, Yong L, Raviola G, Bradford Reich D, et al. 2004. Borderline psychopathology in the first-degree relatives of borderline and axis II comparison probands. J Pers Disord 18(5): 439447. doi: 10.1521 /pedi.18.5.439.51327

47. Roepke S, Vater A, Preißler S, Heekeren HR, Dziobek I. 2013. Social cognition in borderline personality disorder. Front Neurosci 6: 195. doi: 10.3389/fnins.2012.00195

48. Frith CD, Frith U. 2006. The neural basis of mentalizing. Neuron 50(4): 531-534. doi: 10.1016/j.neuron.2006.05.001

49. Mier D, Lis S, Esslinger C, Sauer C, Hagenhoff M, et al. 2013. Neuronal correlates of social cognition in borderline personality disorder. Soc Cogn Affect Neurosci 8(5): 531-537. doi: 10.1093/scan/nss028

50. Premack D, Woodruff G. 1978. Does the chimpanzee have theory of mind? Behav Brain Sci 1: 515-526.

51. Fonagy P, Bateman A. 2008. The development of borderline personality disorder--a mentalizing model.J Pers Disord 22(1): 4-21. doi: 10.1521/ pedi.2008.22.1.4.

52. Linehan MM. 1993. Cognitive behavioral treatment of borderline personality disorder. The Guilford Press, New York, USA.

53. Bateman AW, Fonagy P. 2004. Mentalization-based treatment of BPD. J Pers Disord 18(1): 36-51. doi: 10.1521/pedi.18.1.36.32772

54. Bateman A, Fonagy P. 2009. Randomized controlled trial of outpatient mentalization-based treatment versus structured clinical management for borderline personality disorder. Am J Psychiatry 166(12): 1355-1364. doi: 10.1176/appi.ajp.2009.09040539

55. Goodman M, Siever LJ. 2011. Hypermentalization in adolescents with borderline personality traits: extending the conceptual framework to younger ages. J Am Acad Child Adolesc Psychiatry 50(6): 536-537. doi: 10.1016/j.jaac.2011.02.013

56. Sharp C, Pane H, Ha C, Venta A, Patel AB, et al. 2011. Theory of mind and emotion regulation difficulties in adolescents with borderline traits. J Am Acad Child Adolesc Psychiatry 50(6): 563-573. doi: 10.1016/j. jaac.2011.01.017

57. Choi-Kain LW, Gunderson JG. 2008. Mentalization: ontogeny, assessment, and application in the treatment of borderline personality disorder. Am J Psychiatry 165(9): 1127-1135. doi: 10.1176/appi. ajp.2008.07081360.

58. Dinsdale N, Crespi BJ. 2013. The borderline empathy paradox: evidence and conceptual models for empathic enhancements in borderline personality disorder. J Pers Disord 27(2): 172-195. doi: 10.1521/ pedi.2013.27.2.172

59. Preißler S, Dziobek I, Ritter K, Heekeren HR, Roepke S. 2010. Social cognition in borderline personality disorder: evidence for disturbed 
recognition of the emotions, thoughts, and intentions of others. Front Behav Neurosci 4: 182. doi: 10.3389/fnbeh.2010.00182

60. Beeney JE, Stepp SD, Hallquist MN, Scott LN, Wright AGC, et al. 2015. Attachment and social cognition in borderline personality disorder: Specificity in relation to antisocial and avoidant personality disorders. Personal Disord 6(3): 207-215. doi: 10.1037/per0000110

61. Gallagher HL, Frith CD. 2003. Functional imaging of 'theory of mind'. Trends Cogn Sci 7(2): 77-83. doi: 10.1016/S1364-6613(02)00025-6

62. Haas BW, Miller JD. 2015. Borderline personality traits and brain activity during emotional perspective taking. Personal Disord 6(4): 315320. doi: $10.1037 /$ per0000130.

63. Saxe R, Kanwisher N. 2003. People thinking about thinking people. The role of the temporo-parietal junction in "theory of mind". Neuroimage 19(4): 1835-1842. doi: 10.1016/S1053-8119(03)00230-1

64. Deen B, Koldewyn K, Kanwisher N, Saxe R. 2015. Functional organization of social perception and cognition in the superior temporal sulcus. Cereb Cortex 25(11): 4596-4609. doi: 10.1093/cercor/bhv111

65. Mier D, Sauer C, Lis S, Esslinger C, Wilhelm J, et al. 2010. Neuronal correlates of affective theory of mind in schizophrenia out-patients: evidence for a baseline deficit. Psychol Med 40(10): 1607-1617. doi: 10.1017/S0033291709992133

66. Gallese V, Goldman A. 1998. Mirror neurons and the simulation theory of mind-reading. Trends Cogn Sci 2(12): 493-501. doi: 10.1016/S13646613(98)01262-5

67. Rizzolatti G, Craighero L. 2004. The mirror-neuron system. Annu Rev Neurosci 27: 169-192. doi: 10.1146/annurev.neuro.27.070203.144230

68. Gallese V, Eagle MN, Migone P. 2007. Intentional attunement: mirror neurons and the neural underpinnings of interpersonal relations. $\mathrm{J} \mathrm{Am}$ Psychoanal Assoc 55(1): 131-176. doi: 10.1177/00030651070550010601

69. Dziobek I, Preissler S, Grozdanovic Z, Heuser I, Heekeren HR, et al. 2011. Neuronal correlates of altered empathy and social cognition in borderline personality disorder. Neuroimage 57(2): 539-548. doi 10.1016/j.neuroimage.2011.05.005

70. Dziobek I, Rogers K, Fleck S, Bahnemann M, Heekeren HR, et al 2008. Dissociation of cognitive and emotional empathy in adults with Asperger syndrome using the Multifaceted Empathy Test (MET). J Autism Dev Disord 38(3): 464-473. doi: 10.1007/s10803-007-0486-x

71. Davis M. 1994. Empathy: A social psychological. Westview Press, Boulder, CO, USA

72. O’Neill A, D’Souza A, Samson AC, Carballedo A, Kerskens C, et al. 2015. Dysregulation between emotion and theory of mind networks in borderline personality disorder. Psychiatry Res 231(1): 25-32. doi: 10.1016/j.pscychresns.2014.11.002

73. Samson AC, Zysset S, Huber O. 2008. Cognitive humor processing: different logical mechanisms in nonverbal cartoons--an fMRI study. Soc Neurosci 3(2): 125-140. doi: 10.1080/17470910701745858

74. Ruocco AC, Amirthavasagam S, Choi-Kain LW, McMain SF. 2013. Neural correlates of negative emotionality in borderline personality disorder: An activation-likelihood-estimation meta-analysis. Biol Psychiatry 73(2): 153-160. doi: 10.1016/j.biopsych.2012.07.014

75. Saxe RR, Pelphrey KA. 2009. Introduction to a special section of developmental social cognitive neuroscience. Child Dev 80(4): 946-951. doi: 10.1111/j.1467-8624.2009.01309.x

76. Scholz J, Triantafyllou C, Whitfield-Gabrieli S, Brown EN, Saxe R. 2009. Distinct regions of right temporo-parietal junction are selective for theory of mind and exogenous attention. PLoS One 4: e4869. doi: 10.1371/journal.pone.0004869

77. Skodol AE, Clark L, Bender DS, Krueger RF, Morey LC, et al. 2011 Proposed changes in personality and personality disorder assessment and diagnosis for DSM-5 Part I: Description and rationale. Personal Disord 2(1): 4-22. doi: 10.1037/a0021891

78. Beeney JE, Hallquist MN, Ellison WD, Levy KN. 2016. Self-other disturbance in borderline personality disorder: Neural, self-report, and performance-based evidence. Personal Disord 7(1): 28-39. doi: 10.1037/ per0000127

79. Boehme S, Miltner WH, Straube T. 2015. Neural correlates of selffocused attention in social anxiety. Soc Cogn Affect Neurosci 10(6): 856862. doi: $10.1093 / \mathrm{scan} / \mathrm{nsu} 128$

80. Bögels SM, Mansell W. 2004. Attention processes in the maintenance and treatment of social phobia: hypervigilance, avoidance and selffocused attention. Clin Psychol Rev 24(7): 827-856. doi: 10.1016/j. cpr.2004.06.005

81. King-Casas B, Sharp C, Lomax-Bream L, Lohrenz T, Fonagy P, et al. 2008. The rupture and repair of cooperation in borderline personality disorder. Science 321(5890): 806-810. doi: 10.1126/science.1156902

82. Chang LJ, Smith A, Dufwenberg M, Sanfey AG. 2011. Triangulating the neural, psychological, and economic bases of guilt aversion. Neuron 70(3): 560-572. doi: 10.1016/j.neuron.2011.02.056

83. Shin LM, Dougherty DD, Orr SP, Pitman RK, Lasko M, et al. 2000. Activation of anterior paralimbic structures during guilt-related scriptdriven imagery. Biol Psychiatry 48(1): 43-50. doi: 10.1016/S00063223(00)00251-1

84. Domsalla M, Koppe G, Niedtfeld I, Vollstädt-Klein S, Schmahl C, et al. 2014. Cerebral processing of social rejection in patients with borderline personality disorder. Soc Cogn Affect Neurosci 9(11): 1789-1797. doi: $10.1093 /$ scan/nst176

85. Andrews-Hanna JR, Reidler JS, Sepulcre J, Poulin R, Buckner RL. 2010. Functional-anatomic fractionation of the brain's default network. Neuron 65(4): 550-562. doi: 10.1016/j.neuron.2010.02.005

86. Buckner RL, Andrews-Hanna JR, Schacter DL. 2008. The brain's default network: anatomy, function, and relevance to disease. Ann NY Acad Sci 1124: 1-38. doi: 10.1196/annals.1440.011

87. Barbas H, Ghashghaei H, Dombrowski SM, Rempel-Clower NL. 1999. Medial prefrontal cortices are unified by common connections with superior temporal cortices and distinguished by input from memory-related areas in the rhesus monkey. J Comp Neurol 410(3): 343-367. doi: 10.1002/(SICI)1096-9861(19990802)410:3<343::AID$\mathrm{CNE} 1>3.0 . \mathrm{CO} ; 2-1$

88. Spreng RN, Grady CL. 2010. Patterns of brain activity supporting autobiographical memory, prospection, and theory of mind, and their relationship to the default mode network. J Cogn Neurosci 22(6): 11121123. doi: $10.1162 /$ jocn.2009.21282

89. Van Overwalle F. 2009. Social cognition and the brain: a meta-analysis. Hum Brain Mapp 30(3): 829-858. doi: 10.1002/hbm.20547

90. Mitchell JP, Banaji MR, Macrae CN. 2005. The link between social cognition and self-referential thought in the medial prefrontal cortex. $J$ Cogn Neurosci 17(8): 1306-1315. doi: 10.1162/0898929055002418

91. Legrand D, Ruby P. 2009. What is self-specific? Theoretical investigation and critical review of neuroimaging results. Psychol Rev 116(1): 252-282. doi: $10.1037 / \mathrm{a} 0014172$

92. Kluetsch RC, Schmahl C, Niedtfeld I, Densmore M, Calhoun VD, et al. 2012. Alterations in default mode network connectivity during pain processing in borderline personality disorder. Arch Gen Psychiatry 69(10): 993-1002. doi: 10.1001/archgenpsychiatry.2012.476

93. Wolf RC, Sambataro F, Vasic N, Schmid M, Thomann PA, et al. 2011. Aberrant connectivity of resting-state networks in borderline personality disorder. J Psychiatry Neurosci 36(6): 402-411. doi: 10.1503/ jpn. 100150

94. Carpenter RW, Trull TJ. 2013. Components of emotion dysregulation in borderline personality disorder: a review. Curr Psychiatry Rep 15(1): 335. doi: 10.1007/s11920-012-0335-2

95. Domes G, Schulze L, Herpertz SC. 2009. Emotion recognition in borderline personality disorder-a review of the literature. J Pers Disord 23(1): 6-19. doi: 10.1521/pedi.2009.23.1.6

96. New AS, aan het Rot M, Ripoll LH, Perez-Rodriguez MM, Lazarus S, et al. 2012. Empathy and alexithymia in borderline personality disorder: clinical and laboratory measures. J Pers Disord 26(5): 660-675. doi: 
10.1521/pedi_2012_26_037

97. Yoo SH, Matsumoto D, LeRoux JA. 2006. The influence of emotion recognition and emotion regulation on intercultural adjustment. Int J Intercult Relations 30(3): 345-363. doi: 10.1016/j.ijintrel.2005.08.006

98. Gross JJ. 1999. Emotion Regulation: Past, Present, Future. Cogn Emot 13(5): 551-573. doi: 10.1080/026999399379186

99. Sheppes G, Suri G, Gross JJ. 2015. Emotion regulation and psychopathology. Annu Rev Clin Psychol 11: 379-405. doi: 10.1146/ annurev-clinpsy-032814-112739

100.Domes G, Czieschnek D, Weidler F, Berger C, Fast K, et al. 2008. Recognition of facial affect in Borderline Personality Disorder. $J$ Per Disord 22(2): 135-147. doi: 10.1521/pedi.2008.22.2.135

101.Wagner AW, Linehan MM. 1999. Facial expression recognition ability among women with borderline personality disorder: implications for emotion regulation? J Pers Disord 13(4): 329-344.

102.Bland AR, Williams CA, Scharer K, Manning S. 2004. Emotion processing in borderline personality disorders. Issues Ment Health Nurs 25(7): 655-672. doi: 10.1080/01612840490486692

103.Levine D, Marziali E, Hood J. 1997. Emotion processing in borderline personality disorders. J Nerv Ment Dis 185(4): 240-246.

104.van Zutphen L, Siep N, Jacob GA, Goebel R, Arntz A. 2015. Emotiona sensitivity, emotion regulation and impulsivity in borderline personality disorder: a critical review of fMRI studies. Neurosci Biobehav Rev 51: 64-76. doi: 10.1016/j.neubiorev.2015.01.001

105.Donegan NH, Sanislow CA, Blumberg HP, Fulbright RK, Lacadie C, et al. 2003. Amygdala hyperreactivity in borderline personality disorder: implications for emotional dysregulation. Biol Psychiatry 54(11): 12841293. doi: 10.1016/S0006-3223(03)00636-X

106.Minzenberg MJ, Fan J, New AS, Tang CY, Siever LJ. 2007. Frontolimbic dysfunction in response to facial emotion in borderline personality disorder: an event-related fMRI study. Psychiatry Res Neuroimaging 155(3): 231-243. doi: 10.1016/j.pscychresns.2007.03.006

107.Cullen KR, LaRiviere LL, Vizueta N, Thomas KM, Hunt RH, et al. 2015. Brain activation in response to overt and covert fear and happy faces in women with borderline personality disorder. Brain Imaging Behav. doi: 10.1007/s11682-015-9406-4

108. Cullen KR, Vizueta N, Thomas KM, Han GJ, Lim KO, et al. 2011. Amygdala functional connectivity in young women with borderline personality disorder. Brain Connect 1(1): 61-71. doi: 10.1089/ brain. 2010.0001

109.Koenigsberg HW, Fan J, Ochsner KN, Liu X, Guise KG, et al. 2009. Neural correlates of the use of psychological distancing to regulate responses to negative social cues: a study of patients with borderline personality disorder. Biol Psychiatry 66(9): 854-863. doi: 10.1016/j. biopsych.2009.06.010

110.Schulze L, Domes G, Krüger A, Berger C, Fleischer M, et al. 2011. Neuronal correlates of cognitive reappraisal in borderline patients with affective instability. Biol Psychiatry 69(6): 564-573. doi: 10.1016/j. biopsych.2010.10.025

111.Etkin A, Egner T, Kalisch R. 2011. Emotional processing in anterior cingulate and medial prefrontal cortex. Trends Cogn Sci 15(2): 85-93. doi: $10.1016 /$ j.tics.2010.11.004

112.Pessoa L, Adolphs R. 2010. Emotion processing and the amygdala: from a 'low road' to 'many roads' of evaluating biological significance. Nat Rev Neurosci 11(11): 773-783. doi: 10.1038/nrn2920

113.Koenigsberg HW, Siever LJ, Lee H, Pizzarello S, New AS, et al. 2009. Neural correlates of emotion processing in borderline personality disorder. Psychiatry Res 172(3): 192-199. doi: 10.1016/j. pscychresns.2008.07.010

114.Kim SG, Richter W, UÄŸurbil K. 1997. Limitations of temporal resolution in functional MRI. Magn Reson Med 37(4): 631-636.

115.Guitart-Masip M, Pascual JC, Carmona S, Hoekzema E, Bergé D, et al. 2009. Neural correlates of impaired emotional discrimination in borderline personality disorder: An fMRI study. Prog NeuroPsychopharmacology Biol Psychiatry 33(8) 1537-1545. doi: 10.1016/j. pnpbp.2009.08.022

116.Eickhoff SB, Laird AR, Grefkes C, Wang LE, Zilles K, et al. 2009. Coordinate-based activation likelihood estimation meta-analysis of neuroimaging data: a random- effects approach based on empirical estimates of spatial uncertainty. Hum Brain Mapp 30(9): 2907-2926. doi: 10.1002/hbm.20718

117.Turkeltaub PE, Eickhoff SB, Laird AR, Fox M, Wiener M, et al. 2012 Minimizing within-experiment and within-group effects in Activation Likelihood Estimation meta-analyses. Hum Brain Mapp 33(1): 1-13. doi: 10.1002/hbm.21186

118.Eickhoff SB, Bzdok D, Laird AR, Kurth F, Fox PT. 2012. Activation likelihood estimation meta-analysis revisited. Neuroimage 59(3): 23492361. doi: 10.1016/j.neuroimage.2011.09.017

119. Critchley HD, Mathias CJ, Dolan RJ. 2001. Neuroanatomical basis for first- and second-order representations of bodily states. Nat Neurosci 4(2): 207-212. doi: 10.1038/84048

120.Phillips ML, Williams LM, Heining M, Herba CM, Russell T, et al 2004. Differential neural responses to overt and covert presentations of facial expressions of fear and disgust. Neuroimage 21(4): 1484-1496. doi: 10.1016/j.neuroimage.2003.12.013

121.Menon V, Uddin LQ. 2010. Saliency, switching, attention and control: a network model of insula function. Brain Struct Funct 214(5-6): 655-667. doi: 10.1007/s00429-010-0262-0

122.Seeley WW, Menon V, Schatzberg AF, Keller J, Glover GH, et al. 2007. Dissociable intrinsic connectivity networks for salience processing and executive control. I Neurosci 27(9): 2349-2356. doi: 10.1523/ JNEUROSCI.5587-06.2007

123.Sridharan D, Levitin DJ, Menon V. 2008. A critical role for the right fronto-insular cortex in switching between central-executive and default-mode networks. Proc Natl Acad Sci U S A 105(34): 12569-12574. doi: 10.1073/pnas.0800005105

124.Morawetz C, Holz P, Lange C, Baudewig J, Weniger G, et al. 2008. Improved functional mapping of the human amygdala using a standard functional magnetic resonance imaging sequence with simple modifications. Magn Reson Imaging 26(1): 45-53. doi: 10.1016/j. mri.2007.04.014

125.Hazlett EA, Zhang J, New AS, Zelmanova Y, Goldstein KE, et al. 2012. Potentiated amygdala response to repeated emotional pictures in borderline personality disorder. Biol Psychiatry 72(6): 448-456. doi: 10.1016/j.biopsych.2012.03.027

126.Koeningsberg HW, Denny BT, Fan J, Liu X, Guerreri S, et al. 2014 The neural correlates of anomalous habituation to negative emotional pictures in borderline and avoidant personality disorder patients. $\mathrm{Am} \mathrm{J}$ Psychiatry 171(1): 82-90. doi: 10.1176/appi.ajp.2013.13070852

127.Plichta MM, Grimm O, Morgen K, Mier D, Sauer C, et al. 2014 Amygdala habituation: a reliable fMRI phenotype. Neuroimage 103: 383-390. doi: 10.1016/j.neuroimage.2014.09.059

128.Sauder CL, Hajcak G, Angstadt M, Phan KL. 2013. Test-retest reliability of amygdala response to emotional faces. Psychophysiology 50(11): 1147-1156. doi: 10.1111/psyp.12129

129.Ebner-Priemer UW, Badeck S, Beckmann C, Wagner A, Feige B. 2005. Affective dysregulation and dissociative experience in female patients with borderline personality disorder?: A startle response study. $J$ Psychiatric Res 39(1): 85-92. doi: 10.1016/j.jpsychires.2004.05.001

130.Peters JR, Upton BT, Baer RA. 2013. Brief report: relationships between facets of impulsivity and borderline personality features. $J$ Pers Disord 27(4): 547-552.doi: 10.1521/pedi_2012_26_044

131.Sansone RA, Barnes J, Muennich E, Wiederman MW. 2008. Borderline personality symptomatology and sexual impulsivity. Int J Psychiatry Med 38(1): 53-60. doi: 10.2190/PM.38.1.e

132.Dimeff L, Linehan MM. 2001. Dialectical behavior therapy in a nutshell. The California Psychologist 34(3): 10-13. 
133.Links PS, Heslegrave R, van Reekum R. 1999. Impulsivity: core aspect of borderline personality disorder. J Pers Disord 13(1): 1-9.

134.Sebastian A, Jacob G, Lieb K, Tüscher O. 2013. Impulsivity in borderline personality disorder: a matter of disturbed impulse control or a facet of emotional dysregulation? Curr Psychiatry Rep 15(2): 339 doi: 10.1007/s11920-012-0339-y

135.Domes G,Winter B, Schnell K, Vohs K, Fast K, et al. 2006. The influence of emotions on inhibitory functioning in borderline personality disorder. Psychol Med 36(8): 1163-1172. doi: 10.1017/S0033291706007756

136.Jacob GA, Gutz L, Bader K, Lieb K, Tüscher O. 2010. Impulsivity in borderline personality disorder: Impairment in self-report measures, but not behavioral inhibition. Psychopathology 43(3): 180-188. doi: $10.1159 / 000304174$

137.Weiss NH, Sullivan TP, Tull MT. 2015. Explicating the role of emotion dysregulation in risky behaviors: A review and synthesis of the literature with directions for future research and clinical practice. Curr Opin Psychol 3: 22-29. doi: 10.1016/j.copsyc.2015.01.013

138. Weiss NH, Tull MT, Viana AG, Anestis MD, Gratz KL. 2012. Impulsive behaviors as an emotion regulation strategy: Examining associations between PTSD, emotion dysregulation, and impulsive behaviors among substance dependent inpatients. J Anxiety Disord 26(3): 453-458. doi: 10.1016/j.janxdis.2012.01.007

139.Fossati A, Gratz KL, Maffei C, Borroni S. 2014.Impulsivity dimensions, emotion dysregulation, and borderline personality disorder features among Italian nonclinical adolescents. Borderline Personal Disord Emot Dysregulation 1: 5. doi: 10.1186/2051-6673-1-5

140.Gratz KL, Roemer L. 2004. Multidimensional assessment of emotion regulation and dysregulation: development, factor structure, and initial validation of the difficulties in emotion regulation scale. J Psychopathol Behav Assess 26(1): 41-54. doi: 10.1023/B:JOBA.0000007455.08539.94

141. Crowell SE, Beauchaine TP, Linehan MM. 2009. A biosocial developmental model of borderline personality: Elaborating and extending Linehan's theory. Psychol Bull 135(3): 495-510. doi: 10.1037/ a0015616

142.Berlin HA, Rolls ET, Iversen SD. 2005. Borderline personality disorder, impulsivity, and the orbitofrontal cortex. Am J Psychiatry 162(12): 23602373. doi: 10.1176/appi.ajp.162.12.2360

143.Berlin HA, Rolls ET, Kischka U. 2004. Impulsivity, time perception, emotion and reinforcement sensitivity in patients with orbitofrontal cortex lesions. Brain 127(Pt 5): 1108-1126. doi: 10.1093/brain/awh135

144.Mar AC, Walker AL, Theobald DE, Eagle DM, Robbins TW. 2011. Dissociable effects of lesions to orbitofrontal cortex subregions on impulsive choice in the rat. J Neurosci 31(17): 6398-6404. doi: 10.1523/ JNEUROSCI.6620-10.2011

145.Gay P, Rochat L, Billieux J, d'Acremont M, Van der Linden M. 2008 Heterogeneous inhibition processes involved in different facets of selfreported impulsivity: evidence from a community sample. Acta Psychol (Amst) 129(3): 332-339. doi: 10.1016/j.actpsy.2008.08.010

146. Congdon E, Canli T. 2005. The endophenotype of impulsivity: reaching consilience through behavioral, genetic, and neuroimaging approaches. Behav Cogn Neurosci Rev 4(4): 262-281. doi: $10.1177 / 1534582305285980$

147.Bjork JM, Chen G, Smith AR, Hommer DW. 2010. Incentive-elicited mesolimbic activation and externalizing symptomatology in adolescents. J Child Psychol Psychiatry 51(7): 827-837. doi: 10.1111/j.14697610.2009.02201.x

148.Bjork JM, Knutson B, Hommer DW. 2008. Incentive-elicited striata activation in adolescent children of alcoholics. Addiction 103(8): 13081319. doi: 10.1111/j.1360-0443.2008.02250.x

149.Völlm B, Richardson P, McKie S, Elliott R, Dolan M, et al. 2007. Neuronal correlates of reward and loss in Cluster B personality disorders: a functional magnetic resonance imaging study. Psychiatry Res 156(2): 151-167. doi: 10.1016/j.pscychresns.2007.04.008

150.Gray J. 1987. The psychology of fear and stress. Weidenfeld and
Nicholson, London, UK

151.Beauchaine TP, Klein DN, Crowell SE, Derbidge C, Gatzke-Kopp LM. 2009. Multifinality in the development of personality disorders: A biology x sex x environment interaction model of antisocial and borderline traits. Dev Psychopathol 21(3): 735-770. doi: 10.1017/ S0954579409000418

152. Fossati A, Barratt ES, Carretta I, Leonardi B, Grazioli F, et al. 2004. Predicting borderline and antisocial personality disorder features in nonclinical subjects using measures of impulsivity and aggressiveness. Psychiatry Res 125(2): 161-170. doi: 10.1016/j.psychres.2003.12.001

153.Glenn CR, Klonsky ED. 2010. A multimethod analysis of impulsivity in nonsuicidal self-injury. Personal Disord 1(1): 67-75. doi: 10.1037/ a0017427

154. Kraus A, Valerius G, Seifritz E, Ruf M, Bremner JD, et al. 2010. Scriptdriven imagery of self-injurious behavior in patients with borderline personality disorder: a pilot FMRI study. Acta Psychiatr Scand 121(1): 41-51. doi: 10.1111/j.1600-0447.2009.01417.x

155.Schoenbaum G, Roesch MR, Stalnaker TA, Takahashi YK. 2009. A new perspective on the role of the orbitofrontal cortex in adaptive behaviour. Nat Rev Neurosci 10(12): 885-892. doi: 10.1038/nrn2753

156.Wingenfeld K, Rullkoetter N, Mensebach C, Beblo T, Mertens M, et al. 2009. Neural correlates of the individual emotional Stroop in borderline personality disorder. Psychoneuroendocrinology 34(4): 571-586. doi: 10.1016/j.psyneuen.2008.10.024

157.Bush G, Whalen PJ, Rosen BR, Jenike MA, McInerney SC, et al. 1998. The counting Stroop: an interference task specialized for functional neuroimaging--validation study with functional MRI. Hum Brain Mapp 6(4): 270-282.

158.van Eijk J, Sebastian A, Krause-Utz A, Cackowski S, Demirakca T, et al. 2015. Women with borderline personality disorder do not show altered BOLD responses during response inhibition. Psychiatry Res 234(3): 378-389. doi: 10.1016/j.pscychresns.2015.09.017

159.Silbersweig D, Clarkin JF, Goldstein M, Kernberg OF, Tuescher O, et al. 2007. Failure of frontolimbic inhibitory function in the context of negative emotion in borderline personality disorder. Am J Psychiatry 164(12): 1832-1841.

160.Ongür D, Price JL. 2000. The organization of networks within the orbital and medial prefrontal cortex of rats, monkeys and humans. Cereb Cortex 10(3): 206-219. doi: 10.1093/cercor/10.3.206

161.Jacob GA, Zvonik K, Kamphausen S, Sebastian A, Maier S, et al. 2013. Emotional modulation of motor response inhibition in women with borderline personality disorder: an fMRI study. J Psychiatry Neurosci 38(3): 164-172. doi: 10.1503/jpn.120029

162.Aron AR, Robbins TW, Poldrack RA. 2004. Inhibition and the right inferior frontal cortex. Trends Cogn Sci 8(4): 170-177. doi: 10.1016/j. tics.2004.02.010

163.Goya-Maldonado R, Walther S, Simon J, Stippich C, Weisbrod M, et al. 2010. Motor impulsivity and the ventrolateral prefrontal cortex. Psychiatry Res 183(1): 89-91. doi: 10.1016/j.pscychresns.2010.04.006

164.Potenza MN. 2007. To do or not to do? The complexities of addiction, motivation, self-control, and impulsivity. Am J Psychiatry 164(1): 4-6. doi: 10.1176/appi.ajp.164.1.4

165.Volkow ND, Wang GJ, Fowler JS, Telang F. 2008. Overlapping neuronal circuits in addiction and obesity: evidence of systems pathology. Philos Trans $R$ Soc Lond B Biol Sci 363(1507): 3191-3200. doi: 10.1098/ rstb.2008.0107

166.Holland PC, Gallagher M. 2004. Amygdala-frontal interactions and reward expectancy. Curr Opin Neurobiol 14(2): 148-155. doi: 10.1016/j. conb.2004.03.007

167.Kahnt T, Heinzle J, Park SQ, Haynes JD. 2010. The neural code of reward anticipation in human orbitofrontal cortex. Proc Natl Acad Sci U S A 107(13): 6010-6015. doi: 10.1073/pnas.0912838107

168.Power Y, Goodyear B, Crockford D. 2012. Neural correlates of pathological gamblers preference for immediate rewards during the 
iowa gambling task: an fMRI study. J Gambl Stud 28(4): 623-636. doi: $10.1007 / \mathrm{s} 10899-011-9278-5$

169. Schoenbaum G, Shaham Y. 2008. The role of orbitofrontal cortex in drug addiction: a review of preclinical studies. Biol Psychiatry 63(3): 256-262. doi: 10.1016/j.biopsych.2007.06.003

170.Wilbertz G, Tebartz van Elst L, Delgado MR, Maier S, Feige B, et al. 2012. Orbitofrontal reward sensitivity and impulsivity in adult attention deficit hyperactivity disorder. Neuroimage 60(1): 353-361. doi: 10.1016/j.neuroimage.2011.12.011

171.Ridderinkhof KR, Ullsperger M, Crone EA, Nieuwenhuis S. 2004. The role of the medial frontal cortex in cognitive control. Science 306(5695): 443-447. doi: 10.1126/science.1100301

172. Conklin CZ, Bradley R, Westen D. 2006. Affect regulation in borderline personality disorder. J Nerv Ment Dis 194(2): 69-77. doi: 10.1097/01. nmd.0000198138.41709.4f

173.Glenn CR, Klonsky ED. 2009. Emotion dysregulation as a core feature of borderline personality disorder. J Pers Disord 23(1): 20-28. doi: 10.1521/pedi.2009.23.1.20

174.Lynch TR, Trost WT, Salsman N, Linehan MM. 2007. Dialectical behavior therapy for borderline personality disorder. Annu Rev Clin Psychol 3: 181-205. doi: 10.1146/annurev.clinpsy.2.022305.095229

175.Gratz KL, Tull MT. 2010. Emotion Regulation as a Mechanism of Change in Acceptance- and Mindfulness-based Treatments, Assessing. ed. New Harbinger Publications, Oakland, CA, USA.

176.Gratz KL, Rosenthal MZ, Tull MT, Lejuez CW, Gunderson JG. 2006. An experimental investigation of emotion dysregulation in borderline personality disorder. J Abnorm Psychol 115(4): 850-855. doi: 10.1037/0021-843X.115.4.850

177.Phillips ML, Ladouceur CD, Drevets WC. 2008. A neural model of voluntary and automatic emotion regulation: implications for understanding the pathophysiology and neurodevelopment of bipolar disorder. Mol Psychiatry 13(9): 829, 833-857. doi: 10.1038/mp.2008.65

178.Wager TD, Davidson ML, Hughes BL, Lindquist MA, Ochsner KN. 2008. Prefrontal-subcortical pathways mediating successful emotion regulation. Neuron 59: 1037-1050.

179.Cutuli D. 2014. Cognitive reappraisal and expressive suppression strategies role in the emotion regulation: an overview on their modulatory effects and neural correlates. Front Syst Neurosci 8: 175. doi: 10.3389/fnsys.2014.00175

180.Lang S, Kotchoubey B, Frick C, Spitzer C, Grabe HJ, et al. 2012. Cognitive reappraisal in trauma-exposed women with borderline personality disorder. Neuroimage 59(6): 1727-1734. doi: 10.1016/j. neuron.2008.09.006

181.Goldin PR, McRae K, Ramel W, Gross JJ. 2008. The neural bases of emotion regulation: reappraisal and suppression of negative emotion. Biol Psychiatry 63(6): 577-586. doi: 10.1016/j.biopsych.2007.05.031

182.Ebner-Priemer U, Houben M, Santangelo P, Kleindienst N, Tuerlinckx F, et al.2015. Unraveling affective dysregulation in borderline personality disorder: a theoretical model and empirical evidence. J Abnorm Psychol

\section{4(1): 186-198. doi: 10.1037/abn0000021}

183.Caria A, Veit R, Sitaram R, Lotze M, Weiskopf N, et al. 2007. Regulation of anterior insular cortex activity using real-time fMRI. Neuroimage 35(3): 1238-1246. doi: 10.1016/j.neuroimage.2007.01.018

184.Stanley B, Siever LJ. 2010. The interpersonal dimension of borderline personality disorder: toward a neuropeptide model. Am J Psychiatry 167(1): 24-39. doi: 10.1176/appi.ajp.2009.09050744

185.Doll A, Sorg C, Manoliu A, Wöller A, Meng C, et al. 2013. Shifted intrinsic connectivity of central executive and salience network in borderline personality disorder. Front Hum Neurosci 7: 727. doi: 10.3389/fnhum.2013.00727

186. Wolf RC, Sambataro F, Vasic N, Schmid M, Thomann PA, et al. 2011. Aberrant connectivity of resting-state networks in borderline personality disorder. J Psychiatry Neurosci 36(6): 402-411. doi: 10.1503/ jpn.100150

187.Cuthbert BN, Insel TR. 2013. Toward the future of psychiatric diagnosis: the seven pillars of RDoC. BMC Med 11: 126. doi: 10.1186/1741-7015-11-126

188.Insel T, Cuthbert B, Garvey M, Heinssen R, Pine DS, et al. 2010. Research domain criteria $(\mathrm{RDoC})$ : toward a new classification framework for research on mental disorders. Am J Psychiatry 167(7): 748-751. doi: 10.1176/appi.ajp.2010.09091379

189.Morris SE, Cuthbert BN. 2012. Research Domain Criteria: cognitive systems, neural circuits, and dimensions of behavior. Dialogues Clin Neurosci 14(1): 29-37.

190.Fernandez KC, Jazaieri H, Gross JJ. 2016. Emotion regulation: A transdiagnostic perspective on a new $\mathrm{RDoC}$ domain. Cognit Ther Res 40(3): 426-440. doi: 10.1007/s10608-016-9772-2

191.Lanius RA, Bluhm R., Coupland NJ, Hegadoren KM, Rowe B, et al. 2010. Default mode network connectivity as a predictor of posttraumatic stress disorder symptom severity in acutely traumatized subjects. Acta Psychiatr Scand 121(1): 33-40. doi: 10.1111/j.16000447.2009.01391.x

192.Tursich M, Ros T, Frewen PA, Kluetsch RC, Calhoun VD, et al. 2015. Distinct intrinsic network connectivity patterns of post-traumatic stress disorder symptom clusters. Acta Psychiatr Scand 132(1): 29-38. doi: 10.1111/acps. 12387

193.Zhang Y, Liu F, Chen H, Li M, Duan X, et al. 2015. Intranetwork and internetwork functional connectivity alterations in post-traumatic stress disorder. J Affect Disord 187: 114-121. doi: 10.1016/j.jad.2015.08.043

194.Nieh EH, Kim SY, Namburi P, Tye KM. 2013. Optogenetic dissection of neural circuits underlying emotional valence and motivated behaviors. Brain Res 1511: 73-92. doi: 10.1016/j.brainres.2012.11.001

195.Russ MJ, Campbell SS, Kakuma T, Harrison K, Zanine E. 1999. EEG theta activity and pain insensitivity in self-injurious borderline patients. Psychiatry Res 89(3): 201-214. doi: 10.1016/S0165-1781(99)00113-4

196.Laird AR, Fox PM, Eickhoff SB, Turner JA, Ray KL, et al. 2011. Behavioral interpretations of intrinsic connectivity networks. $J$ Cogn Neurosci 23(12): 4022-4037. doi: 10.1162/jocn_a_00077 